NBER WORKING PAPER SERIES

\title{
THE INTERNATIONAL MONETARY AND FINANCIAL SYSTEM
}

Pierre-Olivier Gourinchas

Hélène Rey

Maxime Sauzet

Working Paper 25782

http://www.nber.org/papers/w25782

\author{
NATIONAL BUREAU OF ECONOMIC RESEARCH \\ 1050 Massachusetts Avenue \\ Cambridge, MA 02138 \\ April 2019
}

This paper was prepared for the Annual Review of Economics, 2019. We thank Richard Portes for comments. Rey is grateful to the ERC (grant 695722) for funding. Gourinchas is grateful to the Clausen Center for funding. Part of this paper was written while Sauzet was visiting the European Central Bank, whose hospitality is gratefully acknowledged. The views expressed in this paper are those of the authors and do not necessarily reflect those of the European Central Bank. The views expressed herein are those of the authors and do not necessarily reflect the views of the National Bureau of Economic Research.

NBER working papers are circulated for discussion and comment purposes. They have not been peer-reviewed or been subject to the review by the NBER Board of Directors that accompanies official NBER publications.

(C) 2019 by Pierre-Olivier Gourinchas, Hélène Rey, and Maxime Sauzet. All rights reserved. Short sections of text, not to exceed two paragraphs, may be quoted without explicit permission provided that full credit, including $(\subset$ notice, is given to the source. 
The International Monetary and Financial System

Pierre-Olivier Gourinchas, Hélène Rey, and Maxime Sauzet

NBER Working Paper No. 25782

April 2019

JEL No. E0,F3,F4,G1

\section{ABSTRACT}

International currencies fulfill different roles in the world economy with important synergies across those roles. We explore the implications of currency hegemony for the external balance sheet of the United States, the process of international adjustment, and the predictability of the US dollar exchange rate. We emphasize the importance of international monetary spillovers, of the exorbitant privilege, and analyze the emergence of a new 'Triffin dilemma'.

Pierre-Olivier Gourinchas

Department of Economics

University of California, Berkeley

530 Evans Hall \#3880

Berkeley, CA 94720-3880

and CEPR

and also NBER

pog@econ.berkeley.edu

Hélène Rey

London Business School

Regents Park

London NW1 4SA

UNITED KINGDOM

and NBER

hrey@london.edu
Maxime Sauzet

Department of Economics

University of California, Berkeley

530 Evans Hall \#3880

Berkeley, CA 94720-3880

msauzet@berkeley.edu 


\section{Introduction}

The intimate links between the rise and fall of great powers and the international monetary and financial system is what makes studying the latter so fascinating. As analyzed by Kindleberger (1976):

In the 19th century, Britain was the leader of the world economic system. Sterling was international money. The public goods consisted of a market for distress goods, provided by British free trade; a countercyclical flow of capital, produced by the City of London; coordination of macro-economic policies and exchange rates provided by the rules of the gold standard, legitimized and institutionalized by usage; a lender of last resort in the Bank of England, after the Bank Act of 1844 was suspended in the crisis. The United States took over leadership after World War II.

For Kindleberger, it was essential that the country at the center of the system, the hegemon, stabilize the workings of the international monetary system. In this view, periods of transitions between great powers such as the 1930s, when the economic influence of the UK diminished while that of the US was still not fully established, are considered to be especially dangerous for economic stability. Furthermore, the economic leadership of the hegemon rarely goes uncontested. As the US became the center country of the international order in the post world war II Bretton Woods system, France became increasingly aware of, and frustrated by, the asymmetries inherent in that new international monetary arrangement. In a press conference on February 4th, 1965, General De Gaulle stated ${ }^{1}$ :

The fact that many states accept, on principle, dollars just as much as gold to compensate if need be the deficits of the US balance of payments, means that the United States can issue external debt freely. Indeed, when the US owe something, they can pay for it, at least in part, with dollars which they can issue, instead of using gold, whose value is real, has to be earned and that one cannot transfer to others without risk and sacrifice. This unilateral facility that the United States has means that the dollar is not an impartial means of international exchange, since it is a means of issuing credit for one state.

On February 16th, 1965, Valéry Giscard d'Estaing, De Gaulle's finance minister, echoed the words of the General and famously summarized them by saying that the country issuing the reserve currency enjoyed an "exorbitant privilege": in case of a deficit, the United States do not have to take restrictive measures. ${ }^{2}$ De Gaulle and Giscard d'Estaing seized on what may be one of the most consequential implications of being the hegemon of the international monetary and financial system: the ability to issue securities that are always

\footnotetext{
${ }^{1}$ Translation of the authors. We are extremely grateful to Georges-Henri Soutou for providing us with the transcript of the press conference. The French version is available at https://fresques.ina.fr/de-gaulle/fichemedia/Gaulle00105/conference-de-presse-du-4-fevrier-1965.html.

${ }^{2}$ As pointed out in Gourinchas \& Rey (2007b), the expression "exorbitant privilege" has been traditionally attributed to De Gaulle but is nowhere to be found in de Gaulle's speeches. It appears however in a press conference of Giscard d'Estaing as reported by Raymond Aron for Le Figaro, February 16, 1965 p.1475 of Les articles du Figaro, vol. II (Editions de Fallois). We also thank Georges-Henri Soutou for showing us this text.
} 
in high demand by the rest of the world. This has profound implications for the process of external adjustment, for international monetary spillovers and, ultimately, for the stability of the international monetary and financial system. This paper explores these questions.

The roles of a dominant international currency, i.e. a currency used outside the borders of its country of issuance, are multifaceted and involve the three classical functions of money: medium of exchange, store of value, and unit of account. As Krugman (1984) clearly described, there are many interactions and synergies between the international use of a currency in its different roles. ${ }^{3}$ These complementarities reinforce the dominance of the hegemon's currency and make it long lasting. Incumbent international currencies are hard to displace. ${ }^{4}$

One of the key fact underpinning the architecture of the international monetary and financial system is that the hegemon provides safe assets to the rest of the world. As shown in Gourinchas \& Rey (2007b), the US is a world banker, long in risky foreign assets and short in risk-free liquid dollar liabilities, which are in high demand by foreign official and private sectors. ${ }^{5}$ This advantage of issuing the reserve currency spills over into other realms, such as the large amounts of private debt issued in US dollars in international markets (Maggiori, Neiman \& Schreger (2018)) and the large share of trade invoiced in US dollar, which stabilizes the terms of trade of the hegemon (Gopinath et al. (2018)). It also goes hand in hand with the monetary policy of the Federal Reserve having an important effect on the global financial cycle, in particular by affecting the balance sheet of large global financial institution and their risk appetite (Miranda-Agrippino \& Rey (2018)). The dollar exchange rate is a key relative price in the world economy whether on goods markets or in international financial markets. Furthermore, issuing the international currency confers to the hegemon excess returns on its net foreign asset position, thus easing the process of international adjustment (Gourinchas \& Rey (2007a)). These excess returns in normal times are however associated with net wealth transfers to the rest of world in global crisis times when the value of US safe assets appreciate while risky asset prices plummet. These wealth transfers reflect the provision of insurance by the hegemon to the rest of the world in times of global turmoil, a process we called "exorbitant duty" in Gourinchas, Rey \& Govillot (2017).

Finally, the asymmetry inherent in a hegemonic system may also create financial fragilities that can ultimately lead to its demise. In the early 1960s, Yale economist Robert Triffin (1961) noted that the United States would not be able to simultaneously provide the international liquidity needed by the global economy, and maintain the value of the dollar in terms of a fixed supply of gold -as required under the Bretton Woods system. Ultimately, either the world would face a growing shortage of international liquidity, or confidence in the value of the dollar would plummet with an unavoidable run on the currency. This is Triffin's wellknown dilemma. His analysis proved prescient. US policymakers, confronted with growing dollar liabilities in excess of their gold backing, experienced a run on the dollar and were eventually forced to abandon the link between dollar and gold. Triffin's analysis, however, was incomplete for, despite the abandonment of the dollar-gold parity, the dominance of the dollar has increased since the collapse of the Bretton Woods system. Paradoxically, once free

\footnotetext{
${ }^{3}$ See also Portes \& Rey (1998) and Eichengreen, Mehl \& Chitu (2017).

${ }^{4}$ In this article we use the name "international currency" or "dominant currency" to characterize the currency of the main economic power (the hegemon), bearing in mind that some other regional currencies may also circulate internationally at the same time.

${ }^{5}$ See also Despres, Kindleberger \& Salant (1966).
} 
from the shackle of a fixed gold parity, the use of the US dollar as an international currency soared to unprecedented levels. Yet, as we will argue, the financial fragilities inherent in a hegemonic system have not disappeared: the Triffin dilemma is still with us, albeit in a subtly different form (Gourinchas \& Rey (2007b), Obstfeld (2011), Gourinchas, Rey \& Govillot (2017), and Farhi \& Maggiori (2018)).

This paper begins with a brief description of the International Monetary System, emphasizing the characteristics and functions of international currencies and their synergies. It discusses the interactions between the monetary policy of the hegemon, international trade and the global financial cycle. Section 3 zooms in on the current hegemon, the United States. It analyzes closely the properties of its external balance sheet, and how its characteristics influence the process of external adjustment. Section 4 focuses on the implications for the US dollar, a key relative price in the world economy. Section 5 explores several possible interpretations of the "exorbitant privilege". Section 6 discusses the possible risks for financial stability of the organization of the international economic and financial system around a hegemon. Section 7 concludes.

\section{The different roles of international currencies}

It has long been recognized that the more people use a certain medium of exchange, the more useful is that medium of exchange. In that sense, money and languages have similar characteristics, and the US dollar is the lingua franca for today's international monetary system. Barter economies face the well-known problem of the "double coincidence of wants" (Jevons , 1875), a problem that money solves naturally. Monetary theorists have used random matching models to analyze the emergence of money as a way to overcome the trading frictions inherent to barter economies (Kiyotaki \& Wright, 1989; Matsuyama, Kiyotaki \& Matsui , 1993; Zhou , 1997; Lagos \& Wright , 2005). In these models, the belief that many people will accept a certain currency unit sustains equilibria in which those monetary units circulate. As a result, welfare is improved: money puts oil in the mechanism of exchange and decreases bilateral trading frictions.

The history of money shows that over time and space, very special objects, in particular those difficult to counterfeit, have played the role of money: shells, rare stones, precious metals, are but a few examples. Trust in the medium of exchange is paramount, so it has to be recognizable and stable in value. In modern days, this implies that it has to be backed by a credible fiscal authority. In turn, stability also makes it a good unit of account. ${ }^{6}$ Hence, there are clear strategic complementarities across the different functions of money. The logic extends to the various roles of an international currency with similar force. Figure 1, taken from ECB (2018), shows the strength of these complementarities. It exemplifies the current dominance of the US dollar in all domains: international debt issuance, international loans, foreign exchange turnover, global payment, and foreign exchange reserves. The euro, a more regional dominant currency, comes a distant second. ${ }^{7}$

\footnotetext{
${ }^{6}$ As an aside, note that so far, cryptocurrencies are clearly not meeting these standards.

${ }^{7}$ For analyses of the rivalry between the euro and the dollar and the future of the dollar order see Alogoskoufis \& Portes (1991), Kenen (2003), Papaioannou, Portes \& Siourounis (2006), Chinn \& Frankel (2007), and Eichengreen (2011).
} 


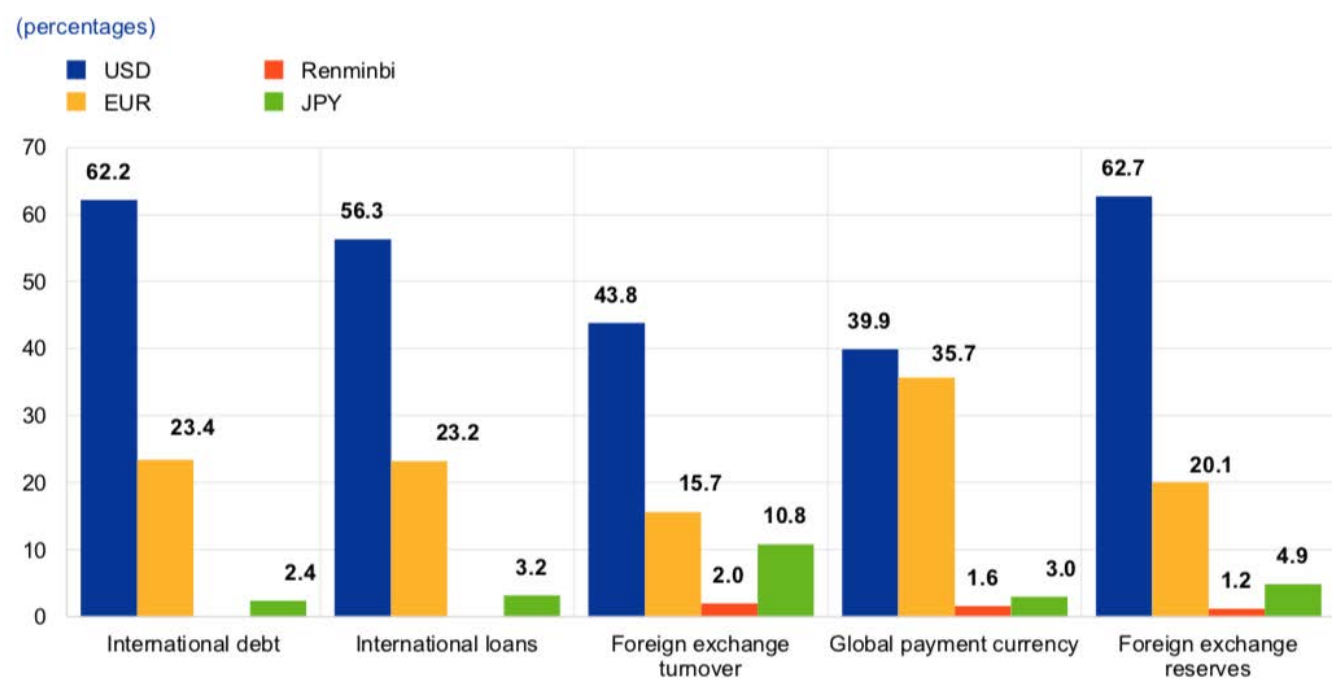

Figure 1: The Dominance of the dollar. Source: ECB Report on the international role of the euro, chart 2, ECB (2018).

Building on the typology of Kenen (1983), Table 1 presents a summary of the different roles of an international currency in the private and official sectors. ${ }^{8}$ The next subsections review these different roles in more details.

Table 1: International currrency

\begin{tabular}{|c|c|c|c|}
\hline & \multicolumn{3}{|c|}{ Roles } \\
\hline & Medium of exchange & Store of value & Unit of account \\
\hline Private sector & $\begin{array}{c}\text { Vehicle currency } \\
\text { Liquid \& safe asset } \\
\text { markets }\end{array}$ & $\begin{array}{c}\text { Nominal securities issuance } \\
\text { Banking, cash hoarding }\end{array}$ & $\begin{array}{l}\text { Denomination of } \\
\text { securities } \\
\text { Trade invoicing }\end{array}$ \\
\hline Official sector & $\begin{array}{l}\text { Intervention currency } \\
\text { Lender of last resort }\end{array}$ & Reserves & Exchange rate pegs \\
\hline
\end{tabular}

Note: Adapted from Kenen (1983).

\subsection{Vehicle currencies, currency of issuance, intervention, and peg}

Let us first consider the role of an international currency as a medium of exchange. As a consequence of strong network externalities, market forces endogenously select a small number of currencies to become vehicle currencies, i.e. favored means of exchange, through which most of the bilateral exchanges in international markets with many different countries take

\footnotetext{
${ }^{8}$ See also Cohen (1971), Kindleberger (1981) and Krugman (1984).
} 
place. For example, on foreign exchange markets, the Malaysian ringgit is rarely exchanged directly against the Mexican peso. Instead, two transactions take place with the dollar in the middle: ringgit are exchanged into dollar, and dollar are exchanged into peso. The bilateral exchange rates verify triangular arbitrage, yet only the more liquid bilateral markets involving the dollar are used to perform transactions. The dollar is the dominant vehicle currency. According to the last triennal survey of the Bank for international Settlement (BIS , 2016), the US dollar was on $87.6 \%$ of all transactions in the foreign exchange market in 2016 (out of a total of $200 \%$ due to a currency being on both side of a trade). The second most used currency was the euro at $31.3 \%$.

This vehicle currency role, closely linked to the liquidity and safety properties of markets in different currencies, has been studied in Krugman (1980), Hartmann (1998), and Rey (2001). Private actors around the globe use dollars to transact and invest their short term funds as they are viewed as the safest and most liquid instrument. Liquidity, i.e. the ability to transact large quantities without an adverse price movement, is central to the quality of a medium of exchange. Safety is essential as well, as it preserves the purchasing power of the currency. It is associated with trust in the issuer, difficulty to cheat or counterfeit currencies, and overall macroeconomic stability in the value of the currency. It is no mystery that in countries lacking basic macroeconomic stability, the national legal tender often gives way to an international currency - usually the dollar. Dollarization followed many episodes of severe domestic monetary instability in Latin America in the 1970s and 1980s, or more recently in Zimbabwe or Venezuela. ${ }^{9}$

The currency of issuance of internationally traded assets is therefore a key determinant of the private sector's demand for stores of value. Using a finely disaggregated dataset of $\$ 27$ trillion in security-level investment positions, Maggiori, Neiman \& Schreger (2018) show that investor holdings are biased toward securities denominated in their own currencies, even when issued by foreign borrowers. This currency bias is very strong. Canadian investors, for instance, mostly hold securities issued in Canadian dollars. Conversely, most Canadian firms issue only in Canadian dollars and their liabilities are held locally. The pattern is different, however, for international currencies like the dollar. Since most investors are willing to hold dollars, this means that even relatively small US firms have little difficulty borrowing from abroad. This reflects the liquidity and depth of US dollar asset markets, amplified by the vehicle currency role described above. It also reflects one aspect of the exorbitant privilege described by Giscard d'Estaing, an aspect to which we come back in Section 5.

Moving to the official sector, Central Bank intervention in foreign exchange markets will use the dominant currency, i.e. the currency in which most market players transact and may need to obtain emergency financing. Therefore, the vehicle currency will also be the intervention currency. Naturally, this intervention currency is also the currency in which most reserves, i.e. the stores of value for the official sector, are held. Figure 2 illustrates this point by showing how the distribution of Central Bank reserves by currency evolved over time: the US dollar constitutes the lion's share of Central Bank reserves, with the euro

\footnotetext{
${ }^{9}$ Rogoff (1998) documents the important use of dollar notes outside US borders, whether for tax evasion or currency substitution purposes. Rogoff (2017) makes a strong case for the elimination of cash to help eradicate corruption, terrorism, the drug trade, human trafficking, and the rest of a large global underground economy.
} 


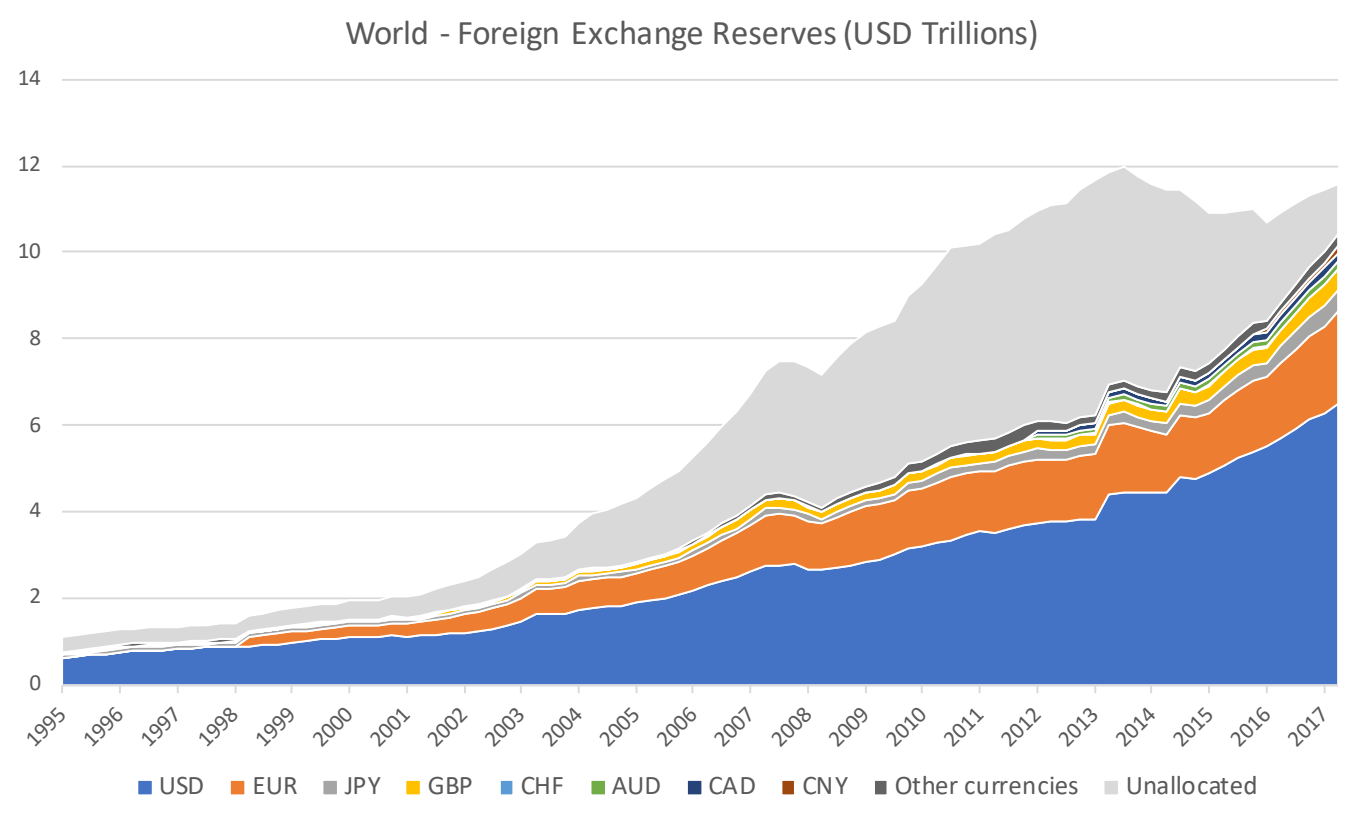

Figure 2: Currency composition of Foreign Exchange Reserves for the World, in trillions of US dollars. Source: IMF COFER. The date indicates the last quarter of each year.

a distant second. These strategic complementarities are further amplified in cases where a country is pegging, de jure or de facto, its own currency to a dominant currency. In order to stabilize its own currency, a Central Bank will need to actively buy and sell the dominant currency. Ilzetzki, Reinhart \& Rogoff (2017) show that the US dollar is by far the world's dominant anchor currency. Surprisingly, its use is even wider nowadays than it was during the Bretton Woods system where most countries formally pegged their currency to the US dollar.

Starting with the importance of liquidity and safety for international currencies, we have discussed important synergies between the roles of money as medium of exchange and store of value in the private sphere (vehicle currency role and nominal securities issuance), its role as intervention currency and exchange rate anchor in the official sector. We now turn to another set of powerful interactions linking trade and securities invoicing (unit of account role) with banking and the lender of last resort role of Central Banks.

\subsection{Trade invoicing, banking, reserves, and lender of last resort}

An important facet of an international currency is its extensive use for trade invoicing. ${ }^{10}$ As Goldberg \& Tille (2009) and Gopinath (2016) discuss, a disproportionate amount of international trade transactions are invoiced in US dollars. To emphasize this point, we use the data from Gopinath (2016) for all available countries, and show in Figure 3 the sum of the share of imports and exports invoiced in dollars, and in euros, respectively. A sum equal to 2 means that $100 \%$ of imports and exports are invoiced in dollars (euros). We observe

\footnotetext{
${ }^{10}$ Trade invoicing is linked to the unit of account role of money. Most of the time, the currency of invoicing is also the currency of transaction, though there are some historical episodes in which they differed. Note that conceptually, they are distinct.
} 
a strong positive correlation between the share of imports and exports invoiced in dollars (euros).
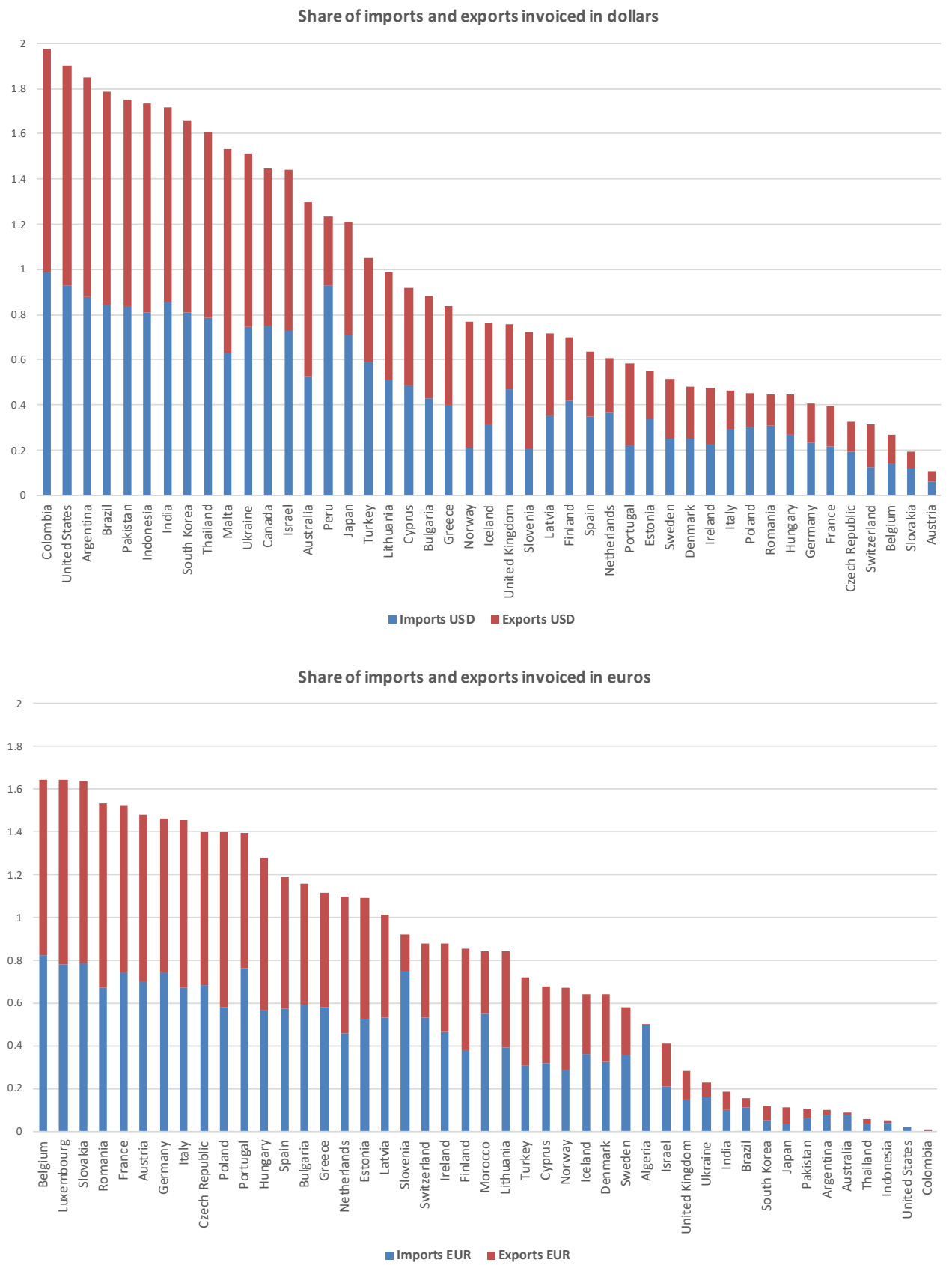

Figure 3: Share of invoice of imports and exports in US dollars and in euros. We keep all the countries for which data on exports and imports are both available. The only exception is the US which we kept in the second graph even though the share of US exports in euros was not available. Source: Gopinath (2016).

A number of countries (besides the US) have a large share of their trade invoiced in dollars. They tend to be emerging markets in Latin America and Asia, but also neighboring countries such as Canada. India has a combined share of about 1.75 in dollar exports and 
imports. On the other hand, European countries invoice largely in euros, which for a number of them is the domestic currency. Overall, there is a clear pattern of dominance of the dollar in the global economy, while the euro is an important regional invoicing currency around Europe. Invoicing currencies would be largely irrelevant if prices were flexible. It is, however, well documented that prices are nominally rigid in the currency in which they are invoiced. As a result, the choice of invoicing currency also affects the pass-through of exchange rate movements into exports and import prices, as analyzed in Gopinath et al. (2018).

There are important complementarities between the use of a currency as a unit of account and as a store of value. For instance, the more trade invoicing is done in a dominant currency, the more likely it is that firms will prefer to hold liquid funds and issue liabilities in that currency. Gopinath \& Stein (2018a) explore the complementarities between trade invoicing and the currency denomination of liabilities in a model where banks are the issuers of safe deposits. A financial claim is only meaningfully safe if it can be used to buy a certain consumption basket at a future date, which depends on the currency in which goods are priced. If imports are invoiced in dollars and these dollar prices are nominally rigid, firms and households will tend to prefer to hold liquid funds (deposits, cash, liquid securities) denominated in dollars to finance future consumption or purchases of intermediate goods. This demand for dollars deposits depresses the dollar interest rate, which in turn induces local financial institutions to intermediate dollar liabilities. As a result, the expected return on dollar deposits is on average lower, in violation of uncovered interest parity. This is one interpretation of the exorbitant privilege associated with the dollar. ${ }^{11}$ Gopinath \& Stein (2018b) also note there are some natural synergies between the dollarization of intermediaries, as described above, and Central Banks' holdings of dollar reserves to perform their lender of last resort function. For many emerging markets, maintaining financial stability requires owning enough reserves in dollars to cover the liquid dollar liabilities of the domestic financial system (Obstfeld, Shambaugh \& Taylor , 2010; Gourinchas , 2012).

Overall, this suggests that the role of the dollar in invoicing (unit of account) associated with price stickiness may lead to the dollarization of bank deposits, and steer the Central Bank to hold dollar reserves to backstop the financial system. These interactions, just as the ones described previously between the vehicle currency role (medium of exchange), issuance, and exchange rate pegs, illustrate some of the possible synergies between the various roles of an international currency. Recent research has only started to explore these interrelated dimensions and the complementarities that sustain the dollar as a dominant currency, even in a world without formal nominal anchors, and there is no doubt that there are more complementarities between the roles illustrated in Table 1. We now however turn to another aspect and examine how the existence of a hegemonic currency affect the functioning of international goods markets, and of international financial markets, through the monetary policy of the hegemon.

\footnotetext{
${ }^{11}$ Chahrour \& Valchev (2018) build a model of international trade as a search process, and show the existence of a similar price effect for the currency emerging as the international medium of exchange.
} 


\subsection{Hegemon monetary policy, global trade, and global financial cycle}

We conclude this section with a discussion of the interactions between the monetary policy of the hegemon, global trade, and the global financial cycle. There are many reasons why currency dominance matters beyond those described above. Some are geopolitical -and we do not discuss them here- others are economic. Our focus in the remainder of this part will be on the potential spillovers associated with the macroeconomic policies of the hegemon.

To begin with, a large literature has shown the importance of different trade invoicing practices for the transmission of monetary policy and more generally of relative prices movements across borders. The first generation of New Keynesian (NK) models assumed that prices were sticky in the currency of the producing country (Producer Currency Pricing, PCP) as in Obstfeld \& Rogoff (1995). A second generation assumed instead that prices were sticky in the currency of the destination market (local currency pricing, LCP) as in e.g. Betts \& Devereux (2000) (see Corsetti, Dedola \& Leduc (2010) for a survey). However, a third pricing assumption seems more realistic: Dominant Currency Pricing (DCP), in which countries price their products in the dominant currency in the international system. The implications of DCP have been explored recently in Gopinath et al. (2018) in a small economy set-up with strategic complementarities in pricing and imported intermediate inputs. The authors show how the dollar (dominant) exchange rate pass-through into export and import prices is high, regardless of the destination or origin of the goods. It follows that movements in the dollar exchange rate transmit into local consumer prices (via imported prices) and imported quantities, while leaving the US largely insulated. Another interesting implication of DCP is that a strengthening of the value of the dominant currency relative to non-dominant ones can negatively impact global trade. In support of this prediction, Gopinath et al. (2018) document that a 1\% U.S. dollar appreciation against all other currencies in the world predicts a 0.6 to $0.8 \%$ decline within a year in the volume of total trade between countries in the rest of the world, controlling for the global business cycle.

Relatedly, Bruno, Kim \& Shin (2018) underline the importance of the US dollar in Global Value Chains (GVC). Because on the balance sheet of firms, inventories enter as assets that must be financed, the authors show that supply chains entail financing needs, mostly provided in dollars, the latter increasing in a non-linear way with the length of the supply chain. The interaction of the prevalence of dollar invoicing and of the extensive use of the dollar as a financing currency for working capital in GVC therefore also tightly links dollar movements with fluctuations in international trade. This latter channel works through a tightening of the financing constraints as opposed to an aggregate demand channel.

Another strand of the literature emphasizes the spillovers of the hegemon's monetary policy via asset markets. The importance of international monetary spillovers and of factors such as the world interest rate in driving capital flows has been pointed out in the classic work of Calvo et al. (1996). Dollar dominance in banking and the dollarisation of cross border claims (see for example Avdjiev et al. (2015, 2016)) imply that US monetary policy impulses get transmitted beyond US borders in international financial markets. Rey (2013) documents the existence of a global financial cycle and that US monetary policy is one of its drivers. Miranda-Agrippino \& Rey (2018) present evidence that US monetary policy gets transmitted across borders via its effect on asset prices, risk premia, credit creation, credit 
flows, and leverage. They find that one global factor, influenced by the Federal Reserve monetary policy, explains about a quarter of the variance of risky asset prices around the world. Jorda et al. (2018) study the synchronization of financial cycles across 17 advanced economies over the past 150 years. They find that the comovement in credit, house prices, and equity prices has reached historical highs in the past three decades, and again estimate an important role of US monetary policy in driving risk premia. Cecchetti et al. (2017) find that a US monetary policy easing has effects of roughly similar magnitude on the risktaking behavior of foreign financial firms than on US firms. Rey (2016) and Gerko \& Rey (2017) show that US monetary policy affects financing conditions even in countries with flexible exchange rate regimes such as Canada or the United Kingdom. This accumulation of evidence puts into question the well-known monetary policy trilemma, according to which a flexible exchange rate regime should enable monetary policy independence. In addition, Bruno \& Shin (2015) show that a strong dollar is associated with tighter credit conditions worldwide. This link between currency appreciation and leverage implies that global liquidity conditions are sensitive to the dollar exchange rate (see also Borio \& Zhu (2008), and Cohen et al. (2017)). Verdelhan (2018) also emphasizes the importance of a dollar factor in pricing bilateral exchange rates. Finally, Bernanke (2017) provides a thorough discussion of the international spillovers of the policy of the US Federal Reserve.

An interesting recent empirical literature uses detailed bank-level data to further investigate the international transmission of monetary policy. A few important examples include Cetorelli \& Goldberg (2012), who use balance-sheet data to study the role of global banks in transmitting liquidity conditions across borders; Morais, Peydró \& Roldán-Peña (2018), who exploit credit registry data of the Mexican Central Bank and study the effect of foreign monetary policy on loan outcomes in Mexico; and Baskaya et al. (2017), who use finely disaggregated Turkish data on bank loans and highlight the importance of bank heterogeneity in the transmission of capital flow shocks to Turkish credit.

On the theoretical front, work on international monetary transmission and the global financial cycle has built on Neo-Keynesian models (see e.g. Mukhin (2017) for a model with endogenous currency choice and an analysis of monetary policy spillovers, Gourinchas (2018) for an analysis of monetary policy spillovers from the U.S. to Chile, and Gertler et al. (2007) for a small open economy model with a financial accelerator). A fruitful research agenda could be to take into account the risk-taking channel of monetary policy. This could in turn provide a theoretical basis for the analysis of macroprudential policy for countries faced with large capital flows.

In summary, a growing body of evidence documents the dominance of the dollar in all the classical functions of an international currency. Surprisingly, the dominance of the dollar has increased, not decreased over time. This dollar dominance has critical implications for the transmission of monetary policy from the center to the periphery, whether by shaping export and import price and quantity responses, or by affecting the balance sheet of large global financial institution, their risk appetite, and the global synchronization of credit and financial cycles. 


\section{External balance sheets and external adjustment}

The previous section described the importance of the US dollar in the international monetary and price system and how it shapes the spillovers from monetary policy at the center. This section zooms in on the United States and analyzes how dollar dominance affects the external adjustment process of the hegemon itself.

The process of external adjustment, i.e. the economic mechanisms through which deficit or surplus countries satisfy their intertemporal budget constraints, has always been deeply intertwined with the organization and workings of the international monetary and financial system. By studying the empirical properties of the former, we can hope to learn about the latter.

According to Hume's classical price-specie flow theory, the settlement of trade imbalances under a gold standard proceeds more or less automatically via shipments of gold reserves. In the postwar era, the International Monetary Fund, created in 1944 as one of Bretton Woods multilateral organizations, was designed specifically to facilitate the external adjustment process of deficit countries, in a system of fixed but adjustable exchange rates. It provided member countries with medium-term borrowing facilities, assorted with various forms of macroeconomic conditionality. That system suffered from two important asymmetries. First, as Keynes noted with some concern at the time of the Bretton Woods negotiations, surplus countries faced little or no pressure to reduce their external balances: countries could choose to transform their trade surpluses into persistent reserve accumulation. Second, the U.S., as the country at the center of the international monetary system, faced little external constraint given its ability to issue the world's reserve currency.

From this perspective, the external accounts and adjustment process of the U.S. are of particularly interest. While the Bretton Woods system crashed de facto in 1971 when the link between the US dollar and gold was severed, the dollar has remained the undisputed world's anchor and reserve currency since then, as discussed previously. ${ }^{12}$ A critical question is whether and how the U.S. external adjustment process has changed over time.

As issuer of the main reserve currency and global provider of liquidity, the United States' external balance sheet exhibits very specific characteristics, described in detail in Gourinchas \& Rey (2007b) and Gourinchas \& Rey (2014). First, gross cross-border positions are large, reflecting the important role of the US dollar in international portfolios and in underpinning international transactions. ${ }^{13}$ Second, the United States has a long position in risky securities, investing abroad in the form of foreign direct investment and equity. ${ }^{14}$ It has a short position in 'safe' securities, issuing a large quantity of bonds, in particular US Treasuries, which are held by the rest of the world as 'safe assets' ${ }^{15}$. Hence, being 'long risky and short safe', the United States has historically played the role of a world banker. Furthermore, almost all of its external liabilities are denominated in dollars, whereas a sizable portion (about two thirds) of its external assets are in foreign currencies.

To illustrate these balance sheet asymmetries, Figure 4 shows the net positions in risky

\footnotetext{
${ }^{12}$ Cf. also Ilzetzki, Reinhart \& Rogoff (2017).

${ }^{13}$ See Lane \& Milesi-Ferretti (2001) and Lane \& Milesi-Ferretti (2007) for seminal contributions on the gross external asset and liability positions of a large number of countries.

${ }^{14}$ Interestingly, this long risky position has declined since 2008 and the onset of the Global Financial Crisis.

${ }^{15}$ For discussions and models of the role of the demand for safe assets, and the ability of the U.S. to provide them, see Caballero et al. $(2008,2016,2017)$.
} 
Net risky and net safe holdings for United States and Rest of the World

(\% of group's respective GDP)

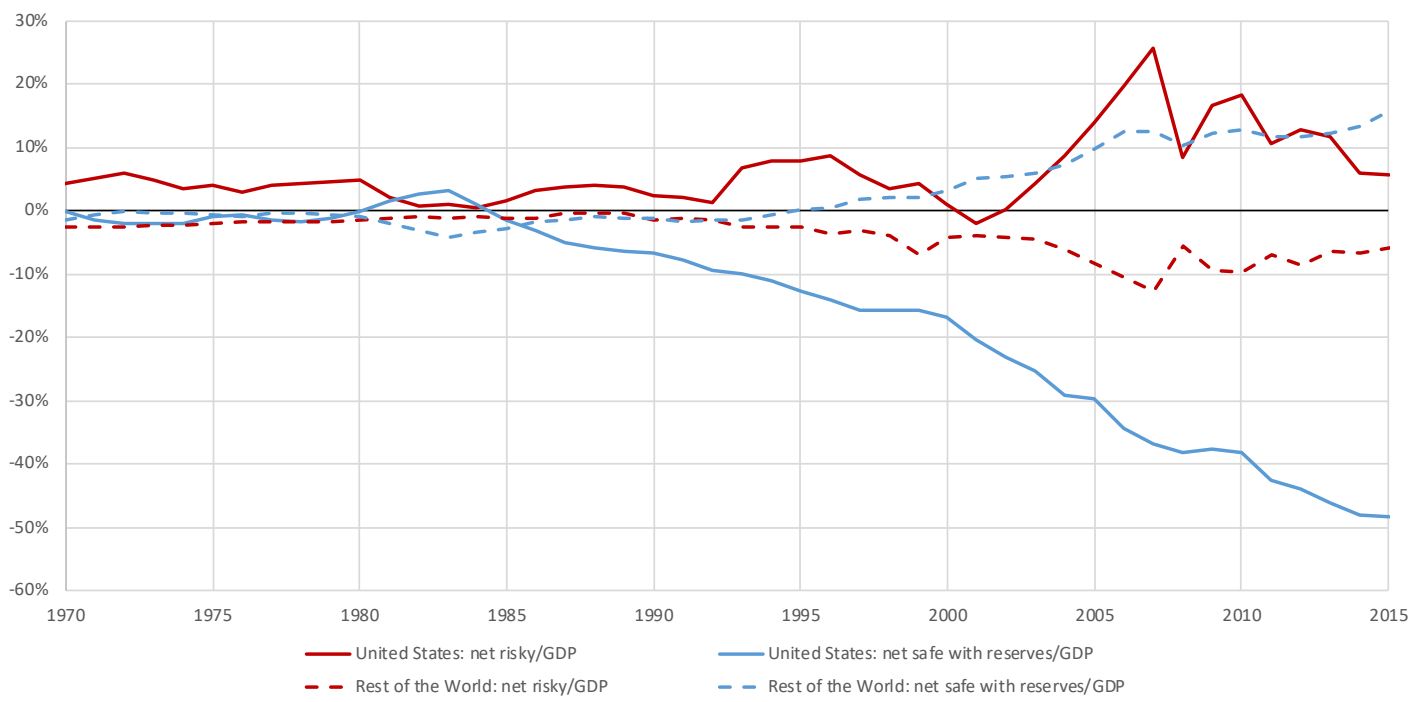

Figure 4: Data are from Lane \& Milesi-Ferretti (2018) and cover 1970-2015 at an annual frequency. Net risky position = portfolio equity assets + FDI assets - (portfolio equity liabilities + FDI liabilities). Net safe position $=$ reserve assets + debt assets - debt liabilities. Debt includes portfolio debt and other investment. Both positions are summed for all countries of each group, U.S. and Rest of the World, and normalized by the GDP of the group in the given year.

assets and safe liabilities for the U.S. and the rest of the world. Data are from Lane \& MilesiFerretti (2018) and cover 1970 to 2015 at the annual frequency. We obtain the net risky position by adding portfolio equity and direct investment assets, and subtracting portfolio equity and direct investment liabilities, and we obtain the net safe position by adding debt (portfolio debt and other investment) and reserve assets, and subtracting debt liabilities. Those measures are then normalized by the total gross domestic product of each country or group. The contrast shown in the Figure is striking: the rest of the world, which includes emerging markets, but also Europe and Japan, have been long safe and short risky since the Asian financial crisis of 1997, while the U.S. is increasingly long risky and, especially, short safe. Within the rest of the world, emerging markets in particular, have been rapidly accumulating safe assets (with a special appetite for US Treasuries) to insure against crises, while financial liberalization has enabled the U.S. - and other advanced economies- to invest in direct investment and portfolio equities abroad.

This asymmetric balance sheet provides both an intermediation margin to the U.S. and a differential valuation response to different types of shocks with important implications for the process of external adjustment. The U.S. earns an intermediation margin in the form of an excess return on its assets (risky) compared to its liabilities (safe). In Gourinchas \& Rey (2007b), getting some inspiration from the famous Giscard d'Estaing quote, we called this excess return the exorbitant privilege. We estimate this excess return at about $2 \%$ a year in real terms for the period 1952-2016 (cf. Gourinchas, Rey \& Govillot (2017)). This enables the United States to run higher external deficits on average. Second, the asymmetry 
in currency composition between assets and liabilities means that exchange rate fluctuations tend to be stabilizing. Everything else equal, a depreciation of the dollar, increases the value of US external assets, while the dollar value of its liabilities remains constant. The net effect is an improvement in the US net external asset position.

This last observation suggests an additional channel of external adjustment, in addition to the standard trade channel emphasized in the literature: because of the composition and size of its external balance sheet, the US external adjustment can operate via future valuation gains or losses. The latter represents what Gourinchas \& Rey (2007a) call the valuation channel of adjustment.

The nature of the US external adjustment process and how it changed over time were initially explored by Gourinchas \& Rey (2007a). The rest of this section revisits and updates their results using more recent data. Crucially, we are now in a position to explore the impact of the Great Recession. We establish three main empirical results. First, the valuation channel has been quite stable or even increasing in importance over time. Second, the trade channel has become markedly less important. These two findings highlight the increasing importance of gross financial flows and positions for the process of external adjustment. Third, the overall forecasting power of -properly measured-external imbalances for external returns or the trade balance remains strong especially at longer horizons, even through the recent crisis. Taken together, these results indicate that an increasingly large share of the US adjustment process occurs through systematic convenience (safety or liquidity) yields earned on its external liabilities, relative to its external assets. This confirms that the U.S. and its currency occupy an increasingly central place in the international financial system, despite the relative decline of the US economy relative to world GDP.

\subsection{External adjustment}

We build on the approach of Gourinchas \& Rey (2007a) who found that valuation effects represent roughly one-third of the cyclical external adjustment of the United States over the 1952Q1-2004Q1 period.

The intuition for their approach is easy to grasp using a simplified framework. Consider the following log-linearized accumulation equation for the US net foreign asset position:

$$
\Delta n a_{t+1} \equiv n a_{t+1}-n a_{t} \approx r_{t+1}+(R-1)\left(n a_{t}+n x_{t}\right)
$$

Here, $n a_{t}$ represents the cyclical component of the net foreign asset position, constructed from estimates of gross external assets and liabilities, $n x_{t}$ represents the cyclical component of the trade balance, constructed from exports and imports, $r_{t+1}$ is the (log) return on the net foreign asset position, i.e. a weighted return on gross external assets and gross external liabilities, and $R>1$ is the steady state gross return on the net foreign asset position. ${ }^{16}$ Eq. (1) states that the US net foreign asset position improves $\left(\Delta n a_{t+1}>0\right)$ either when the US runs a larger trade surplus $\left(n x_{t}>0\right)$ or when the US earns higher returns on its assets than its liabilities $\left(r_{t+1}>0\right)$.

\footnotetext{
${ }^{16}$ For details on how to obtain this log-linearized accumulation equation, we refer the reader to Gourinchas \& Rey (2007a). The cyclical components of the net foreign asset position and the trade balance are extracted using a very smooth Hodrick-Prescott filter with the smoothing parameter set so that the frequency gain of the filter is equal to $70 \%$ at the frequency corresponding to a 50 -year cycle.
} 
One can define a measure of cyclical external imbalances, $n x a_{t}=n a_{t}+n x_{t}$, manipulate and iterate Eq. (1) forward, impose a no-Ponzi condition, and take expectations to obtain:

$$
n x a_{t} \approx-\sum_{j=1}^{+\infty} \frac{1}{R^{j}} \mathbb{E}_{t}\left[r_{t+j}+\Delta n x_{t+j}\right] \equiv n x a_{t}^{r}+n x a_{t}^{\Delta n x}
$$

Eq. (2) is the key empirical equation for our analysis. It shows that movements in the cyclical trade balance and net foreign asset position encoded in $n x a_{t}$ must forecast either future external portfolio returns or future net export growth, or both.

An important advantage of this approach is that it imposes only minimal theoretical restrictions: a dynamic accumulation equation, a no-Ponzi condition, and a log-linearization. The first ingredient is an accounting relation that must be satisfied. The second condition could be violated if, for instance, markets incorrectly expect some external bailout or fail to anticipate a default on external debt. As for the log-linearization, its accuracy depends on the size of the underlying shocks. Consequently, Eq. (2) provides a natural way to let the data speak about which channel of adjustment is most important in practice. A finding that the U.S. external balance condition needs to be satisfied entirely via future trade surpluses (the trade channel), as encoded in $n x a_{t}^{\Delta n x}$ would indicate that the U.S. position at the center of the international monetary system does not grant the country much additional flexibility. By contrast, a finding that the U.S. external balance position can be satisfied via future expected valuation gains (the valuation channel), as encoded in $n x a_{t}^{r}$, would indicate that the U.S. extracts a substantial benefit from its position at the center of the international monetary system, relaxing the need to generate future trade surpluses. Importantly, adjustments through returns can occur via changes in the dollar exchange rate as described above.

To estimate Eq. (2), we construct $n x a_{t}$ from quarterly estimates of the US gross external asset and liability positions at market value, as well as exports and imports, between 1952Q1 and 2015Q4. In the spirit of Campbell \& Shiller (1988), we use a simple reduced form Vector Auto-Regression (VAR) to decompose $n x a_{t}$ in its different subcomponents, namely $n x a_{t}^{r}$ the part related to valuation adjustments, and $n x a_{t}^{\Delta n x}$ the part related to net exports. ${ }^{17}$ Further, $n x a_{t}^{r}$ is decomposed into asset and liability return components $n x a_{t}^{r a}, n x a_{t}^{r l}$, and both are in turn decomposed into equity, FDI, debt, and "other" (bank loans and trade credit) components. We denote them $n x a_{t}^{\text {ria }}, n x a_{t}^{\text {ril }}$ for $i \in\{e, f, d, o\}$. The data and methodology follow Gourinchas \& Rey (2007a) closely, to which we refer the reader for details.

\subsection{Trade and valuation channels of adjustment: quantification}

The first panel of Figure 5 reports the decomposition of the cyclical imbalance measure $n x a_{t}$ into future valuation adjustment $n x a_{t}^{r}$ and future net export adjustment $n x a_{t}^{\Delta n x}$. The second panel breaks down the return component into an asset part and a liability part ${ }^{18}$.

To get a sense of the long-run properties of $n x a_{t}$, we also report in Table 2 a variance decomposition into each subcomponents following Cochrane (1992). Table 2 presents the decomposition for different values of the discount rate $R^{-1}$, and for both our extended

\footnotetext{
${ }^{17}$ The VAR includes $r_{t}, \Delta n x_{t}$ and $n x a_{t}$. We choose the order of the VAR, $p=1$, according to standard lag-selection criteria.

${ }^{18}$ The subcomponents by investment type are reported in Figure A1 of the Appendix.
} 

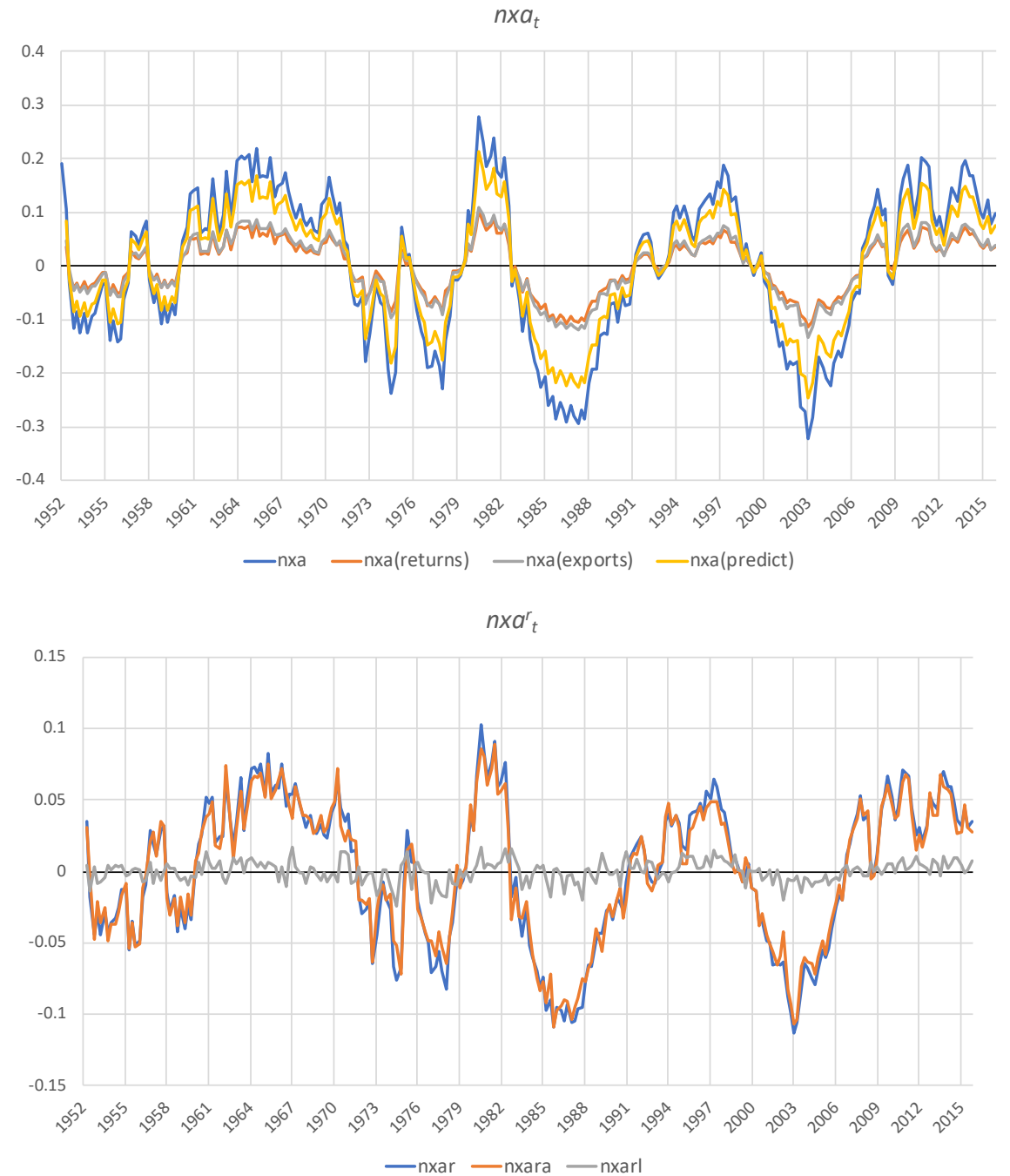

Figure 5: A. Decomposition of $n x a_{t}$ into return $n x a_{t}^{r}$, net exports $n x a_{t}^{\Delta n x}$, and total predicted $n x a$ (predict) components. B. Decomposition of $n x a_{t}^{r}$ into asset return $n x a_{t}^{r a}$ and liability return $n x a_{t}^{r l}$ components.

sample (1952Q1 to 2015Q4) and the original sample of Gourinchas \& Rey (2007a) (1952Q1 to 2004Q1). ${ }^{19}$

Several features are noteworthy. First, the overall fit of the decomposition is good, as evidenced by the fact that predicted $n x a_{t}$, equal to $n x a_{t}^{r}+n x a_{t}^{\Delta n x}$, is closely tracking actual $n x a_{t}$. More precisely, Table 2 shows that together, $n x a_{t}^{r}$ and $n x a_{t}^{\Delta n x}$ explain around $75 \%$ of all $n x a_{t}$ variations for our benchmark value of $R^{-1}=0.95$. Although this does not match the $91 \%$ explained in the original sample, we find those results to be surprisingly good given

${ }^{19}$ Specifically, we decompose the variance as follows:

$$
1=\frac{\operatorname{cov}(n x a, n x a)}{\operatorname{var}(n x a)}=\frac{\operatorname{cov}\left(n x a^{r}, n x a\right)}{\operatorname{var}(n x a)}+\frac{\operatorname{cov}\left(n x a^{\Delta n x}, n x a\right)}{\operatorname{var}(n x a)} \equiv \beta_{r}+\beta_{\Delta n x}
$$

In practice, $\beta_{\mathrm{s}}$ are equivalent to the coefficients from regressing each part independently on $n x a_{t}$. We proceed similarly to obtain each detailed subcomponent. 
that the sample is now longer and includes periods of extreme variations with the Great Recession and euro area crisis. Second, as in Gourinchas \& Rey (2007a), $n x a_{t}^{r}$ and $n x a_{t}^{\Delta n x}$ are positively correlated, i.e. the valuation and trade effects are mutually reinforcing. This underlines the stabilizing role of capital gains in the external adjustment of the United States. In particular, dollar depreciations can be associated both with an improvement in net exports and with a capital gain on the net foreign asset position. Third, valuation effects continue to be particularly important as they explain about $34 \%$ of the cyclical external adjustment of the United States, which is higher than the $30 \%$ found in Gourinchas \& Rey (2007a). In relative terms, the results are even more striking with valuation effects explaining almost as much as trade adjustments (34\% vs. 41\%) while they were less than half as important for 1952Q1-2004Q1 (30\% vs. 63\%). This reflects to some extent the deterioration of the overall fit but also suggests that valuation changes have been particularly substantial during the recent crisis period. In order to gain further insights on those changes, we estimate the same unconditional variance decomposition on a rolling basis with 15 -year windows. ${ }^{20}$ This exercise is reported in Figure 6, with $\beta_{p}=\beta_{r}+\beta_{\Delta n x}$ representing the overall quality of the fit. While net exports account for a large share of the variance until the collapse of the dot-com bubble, their influence declines substantially subsequently while the influence of valuation effects gradually rises. As a result, while the overall fit of the decomposition declines, the deterioration remains limited.

We attribute the decrease in the overall fit to the large fluctuations in asset prices occurring during the global financial crisis of 2008 and the subsequent Eurozone debt crisis of 2010. We observe in particular a dramatic but temporary drop in the overall fit $\left(\beta_{p}\right)$ after the collapse of Lehman Brothers in 2008, when the dislocation in financial markets was most severe. This episode is associated with extreme movements in asset prices and with a negative co-movement of the net export growth component with $n x a_{t}$ (see Gourinchas, Rey \& Govillot (2017) for further discussion). It is likely that the quality of the log-linearization behind Eq. (1) deteriorates significantly when asset markets experience a severe adjustment. Nevertheless, our methodology indicates an increased importance of the valuation component, in an environment of increasingly large cross-border holdings.

Note that for both samples, the asset side is driving the vast majority of valuation changes. For instance, as shown in Table 2, nxa $a_{t}^{r a}$ explains around $27 \%$ of the overall variations in $n x a_{t}$ in the extended sample, versus $7 \%$ for $n x a_{t}^{r l}$. This is also clear from Panel (b) in Figure 5. Lastly, in terms of investment types, FDI and equity explain the bulk of valuation changes on the asset-side ( $14 \%$ and $9 \%$ respectively), while the "other" category, which includes in particular bank loans and trade credits, accounts for the remaining $3 \%$, and debt is small. For liabilities, equity and FDI contribute in equal amount (2.5\%), debt contributes slightly less (1.5\%), and other liabilities are negligible. Those findings are consistent with the composition of the United States external balance sheet being highly asymmetric both in terms of risk taking as it is long in risky assets (equity and FDI) and short in safe assets (debt and other), and also in currency composition, assets being mainly denominated in foreign currency and liabilities in dollars.

\footnotetext{
${ }^{20}$ For this exercise, we reconstruct our estimate of $n x a_{t}$ for each rolling window. This ensures that there is no look-ahead bias: the decomposition at time $t$ does not incorporate information from time $s>t$.
} 
Table 2: Unconditional Variance Decomposition of nxa

\begin{tabular}{lrrrrrr}
\hline & \multicolumn{2}{c}{$\begin{array}{c}\text { Extended sample } \\
(\mathbf{1 9 5 2 Q 1 - 2 0 1 5 Q 4 )}\end{array}$} & \multicolumn{3}{c}{$\begin{array}{c}\text { Original sample } \\
\text { (1952Q1-2004Q1) }\end{array}$} \\
\hline Discount factor $\left(R^{-1}\right)$ & 0.96 & 0.95 & 0.94 & 0.96 & 0.95 & 0.94 \\
\hline$\beta_{\Delta n x}$ & 50.47 & 40.72 & 33.39 & 70.78 & 62.67 & 55.60 \\
$\beta_{r}$ & 31.33 & 34.03 & 34.87 & 26.40 & 30.18 & 32.37 \\
$\beta_{\text {ra }}$ & 25.96 & 27.13 & 27.04 & 18.14 & 18.43 & 17.90 \\
$\beta_{\text {rda }}$ & 0.62 & 0.63 & 0.62 & 0.15 & 0.09 & 0.04 \\
$\beta_{\text {rea }}$ & 8.79 & 9.17 & 9.12 & 7.27 & 7.57 & 7.51 \\
$\beta_{\text {rfa }}$ & 13.30 & 14.18 & 14.34 & 10.62 & 11.15 & 11.15 \\
$\beta_{\text {roa }}$ & 3.24 & 3.14 & 2.95 & 0.10 & -0.38 & -0.81 \\
$\beta_{\text {rl }}$ & 5.37 & 6.90 & 7.83 & 8.26 & 11.75 & 14.47 \\
$\beta_{\text {rdl }}$ & 1.05 & 1.46 & 1.72 & 2.56 & 3.42 & 4.04 \\
$\beta_{\text {rel }}$ & 2.09 & 2.48 & 2.68 & 1.73 & 2.64 & 3.38 \\
$\beta_{\text {rfl }}$ & 2.20 & 2.55 & 2.71 & 1.84 & 2.68 & 3.35 \\
$\beta_{\text {rol }}$ & 0.03 & 0.41 & 0.72 & 2.14 & 3.02 & 3.70 \\
\hline Total $\left(\beta_{p}\right)$ & 81.80 & 74.76 & 68.26 & 97.18 & 92.85 & 87.96 \\
\hline
\end{tabular}

Notes: $\beta_{\Delta n x}\left(\beta_{r}\right)$ represents the share of the unconditional variance of $n x a$ explained by future net export growth (future excess returns). $\beta_{r a}\left(\beta_{r l}\right)$ represents the share of the unconditional variance of $n x a^{r}$ explained by future returns on gross external assets (liabilities). $\beta_{\text {ria }}, \beta_{\text {ril }}$ are the share of the unconditional variance explained by each subcategory of external assets (liabilities): $i \in\{$ debt, equity, FDI, other $\}$. Results for the original sample differ slightly from Gourinchas \& Rey (2007a) because we re-estimate coefficients at the more detailed level using each subcomponent of $n x a^{r a}$ and $n x a^{r l}$. 
(a) Quarterly 15-year rolling window estimate of $\beta_{\Delta \mathrm{nx}}$

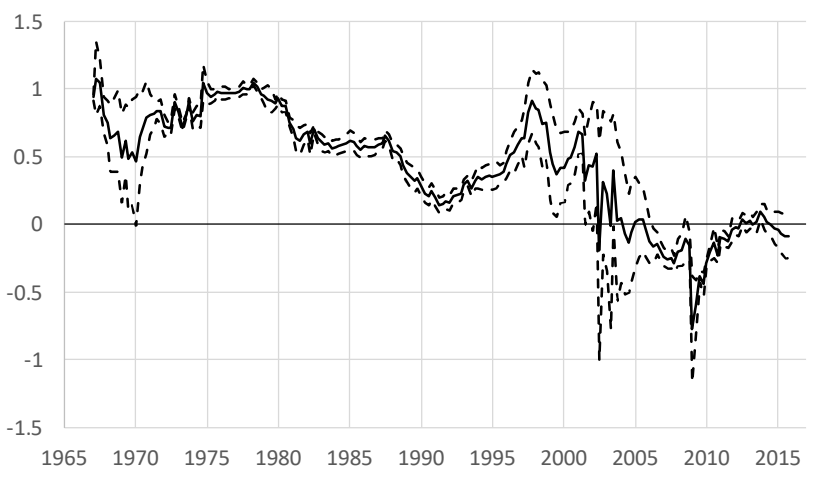

(c) Quarterly 15-year rolling window estimate of $\beta_{p}$

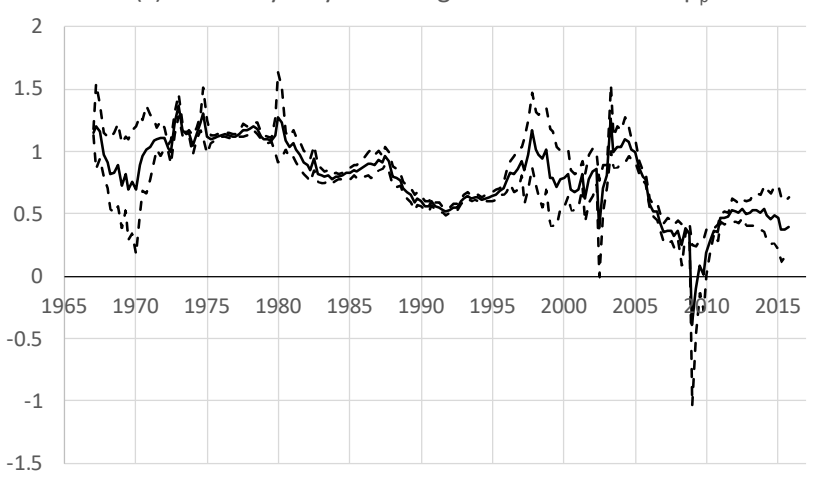

(b) Quarterly 15-year rolling window estimate of $\beta_{r}$

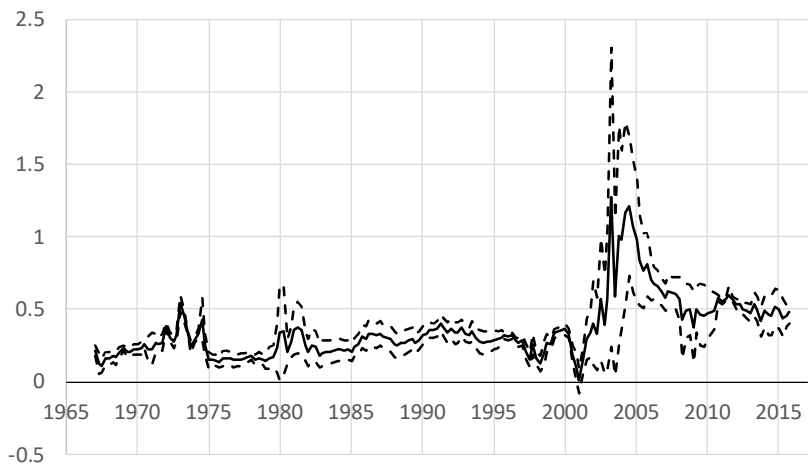

Figure 6: Rolling regressions equivalent of Table 2. In Panels (a) and (b), $\beta_{\Delta n x}$ and $\beta_{r}$ represent the share of the unconditional variance of $n x a$ explained by future net export growth and future excess returns, respectively. They are estimated by regressing $n x a^{\Delta n x}$ and $n x a^{r}$ on $n x a$ over 15-year rolling windows. In Panel (c), $\beta_{p}$ captures the overall quality of the fit. Bands are $95 \%$ confidence intervals based on Newey-West standard-errors. The full sample is 1952Q1-2015Q4. The date is the end of each rolling window.

In conclusion, our empirical analysis of Eq. (2) reveals that the valuation channel of adjustment has increased over time, even while the global economy and financial markets experienced substantial dislocation. If anything, this points to an increased dominance of the US dollar as the international reserve currency and store of value.

\subsection{Predictability of the trade and adjustment channels}

According to our results, a substantial share of the adjustment process operates via future valuation gains. A direct implication is that the US external imbalances, as measured by $n x a_{t}$, must forecast future external portfolio returns $r_{t+j}$, future net export growth $\Delta n x_{t+j}$, or both, at least at some horizons. Evidence of return predictability would confirm that the US external adjustment process has profound implications for global asset markets as well as currency markets (we explore the latter specifically in the next section).

To test this empirical prediction, we run short-term predictive regressions for returns on 
the US net external position. These regressions take the following form:

$$
y_{t+1}=\alpha+\beta n x a_{t}+\delta z_{t}+\epsilon_{t+1}
$$

where $y_{t+1}$ is a quarterly return between $t$ and $t+1, z_{t}$ represents additional controls used in the literature, and $\epsilon_{t+1}$ is a residual. Table 3 presents the results for both samples.

Table 3: Forecasting Quarterly Returns

\begin{tabular}{|c|c|c|c|c|c|c|c|c|}
\hline \multirow[b]{3}{*}{$z_{t}:$} & \multicolumn{8}{|c|}{ Panel A: Extended sample (1952Q1-2015Q4) } \\
\hline & \multicolumn{4}{|c|}{ Total real return $\left(r_{t+1}\right)$} & \multicolumn{4}{|c|}{ Real Equity Differential $\left(\Delta r_{t+1}^{e}\right)$} \\
\hline & & $r_{t}$ & $\frac{d_{t}}{p_{t}}-\frac{d_{t}^{*}}{p_{t}^{*}}$ & $x m_{t}$ & & $\Delta r_{t}^{e}$ & $\frac{d_{t}}{p_{t}}-\frac{d_{t}^{*}}{p_{t}^{*}}$ & $x m_{t}$ \\
\hline$\hat{\beta}$ & -26.31 & -24.24 & -33.45 & -21.46 & -11.22 & -11.14 & -14.63 & -6.41 \\
\hline (s.e.) & $(5.49)$ & $(5.00)$ & $(6.97)$ & $(9.84)$ & $(2.15)$ & $(2.15)$ & $(2.74)$ & $(3.50)$ \\
\hline$\hat{\delta}$ & & 13.18 & -129.31 & -8.60 & & 1.43 & -65.20 & -8.53 \\
\hline (s.e.) & & $(6.38)$ & $(146.18)$ & $(13.66)$ & & $(6.02)$ & $(58.31)$ & $(4.93)$ \\
\hline $\bar{R}^{2}$ & 0.08 & 0.09 & 0.11 & 0.08 & 0.07 & 0.07 & 0.12 & 0.08 \\
\hline \multirow[t]{3}{*}{ \# obs } & 255 & 254 & 137 & 255 & 255 & 254 & 137 & 255 \\
\hline & \multicolumn{8}{|c|}{ Panel B: Original sample (1952Q1-2004Q1) } \\
\hline & \multicolumn{4}{|c|}{ Total real return $\left(r_{t+1}\right)$} & \multicolumn{4}{|c|}{ Real Equity Differential $\left(\Delta r_{t+1}^{e}\right)$} \\
\hline$z_{t}:$ & & $r_{t}$ & $\frac{d_{t}}{p_{t}}-\frac{d_{t}^{*}}{p_{t}^{*}}$ & $x m_{t}$ & & $\Delta r_{t}^{e}$ & $\frac{d_{t}}{p_{t}}-\frac{d_{t}^{*}}{p_{t}^{*}}$ & $x m_{t}$ \\
\hline$\hat{\beta}$ & -35.73 & -32.78 & -45.99 & -36.66 & -13.46 & -13.63 & -16.64 & -7.27 \\
\hline (s.e.) & $(7.26)$ & $(7.26)$ & $(8.42)$ & (15.87) & (3.01) & (3.14) & $(3.30)$ & $(5.80)$ \\
\hline & & 8.87 & -142.96 & 1.31 & & -0.85 & -63.49 & -8.72 \\
\hline (s.e.) & & $(7.30)$ & (159.58) & (18.59) & & $(6.90)$ & (61.08) & $(6.82)$ \\
\hline $\bar{R}^{2}$ & 0.10 & 0.10 & 0.15 & 0.10 & 0.07 & 0.07 & 0.12 & 0.08 \\
\hline \# obs & 208 & 207 & 136 & 208 & 208 & 207 & 136 & 208 \\
\hline
\end{tabular}

Notes: Regressions of the form: $y_{t+1}=\alpha+\beta n x a_{t}+\delta z_{t}+\epsilon_{t+1}$ where $y_{t+1}$ is the total real return $\left(r_{t+1}\right)$ or the equity return differential $\left(\Delta r_{t+1}^{e}=r_{t+1}^{a e}-r_{t+1}^{l e}\right) \cdot \frac{d_{t}}{p_{t}}-\frac{d_{t}^{*}}{p_{t}^{*}}$ is the relative dividend price ratio (available from 1970Q1 to 2004Q2), and $x m_{t}$ is the stationary component from the trade balance. Robust standard errors in parentheses. $\bar{R}^{2}$ is the adjusted- $R^{2}$. Boldface entries are significant at the 5 percent level. All coefficients and standard errors are multiplied by 100 .

The most striking result is that, despite the fact that our extended sample includes the very turbulent recent economic period, the predictive power of $n x a_{t}$ for the returns on the US external portfolio remains very strong. This is true if we look both at $r_{t+j}$, the future returns on the net foreign asset portfolio defined in Gourinchas \& Rey (2007a), and $\Delta r_{t+j}^{e}=r_{t+j}^{a e}-r_{t+j}^{l e}$, the equity returns differential. The adjusted- $R^{2}$ of the regression is $7-8 \%$, and the negative and significant coefficients indicate that a positive deviation from trend $\left(n x a_{t}>0\right)$ predicts a decline in net portfolio return that is qualitatively consistent with Equation 2. Adding controls -lagged values, relative dividend-price ratios and the stationary component of the trade balance- makes virtually no difference, and $n x a_{t}$ remains 
a very strong predictor.

Most importantly, the predictive power of the variable is not only significant, but also economically large: a one-standard-deviation increase in $n x a_{t}(13.97 \%)$ predicts a decline in the net external portfolio return of 368 basis points $(0.1397 \times 26.31 / 100)$ over the next quarter, or about $15.53 \%$ in annualized terms, and a decline in the real equity returns differential of 157 basis points $(0.1397 \times 11.22 / 100)$, or $6.42 \%$ in annualized terms. Hence, $n x a_{t}$ turns out to have a remarkably robust predictive power for the excess returns on the external balance sheet of the hegemonic country throughout the post World War II period, and across multiple exchange rate regimes.

Another way to observe the resilience of the predictability relationship through time is to run our predictive regressions on a rolling basis. The result of this exercise is presented in Figure 7. Each panel shows the coefficient $\beta_{t}$ of a regression similar to Equation 4 run on a 15-year rolling window ${ }^{21}$. We take as $y_{t+1}$ the future returns on the net foreign asset portfolio $r_{t+1}($ panel $(\mathrm{e}))$, the future differential returns for equity $\left(\Delta r_{t+1}^{e}\right)$ (panel(a)) as in Table 2, but also add the future differential returns for FDI $\left(\Delta r_{t+1}^{f}\right)$ (panel (b)), debt $\left(\Delta r_{t+1}^{d}\right)$ (panel $\left.(\mathrm{c})\right)$, and other investment $\left(\Delta r_{t+1}^{o}\right)($ panel $(\mathrm{d}))$.

The graphs confirm the results of Table 2. Except for brief periods around the collapse of the Bretton Woods system and the burst of the dot-com bubble, the coefficients for net returns and equity returns differential stay of roughly the same magnitude. Panels (a) to (d) are also consistent with Table 2 and the variance decomposition results: most of the predictability seems concentrated on equity and FDI returns, with weaker predictability for debt and other investment returns. Two additional facts are notable. First, $n x a_{t}$ did seem to negatively predict returns differential on debt and other investments from around 1985 to 1995. This period is characterized by large debt and bank flows in international capital flows as many emerging markets liberalized their risky asset markets around 1990s or later. Second, we emphasize that when there is predictability, we predict relative returns. In contrast, we find very limited evidence of predictability for the level of returns on gross assets (gross equity and gross FDI assets), and no evidence of predictability for returns on gross liabilities.

Finally, from Equation 2, the predictability has no reason to be limited to the next quarter. We conclude this part by turning to long-horizon regressions in which we regress $k$-horizon average returns, $y_{t, k} \equiv k^{-1} \sum_{i=1}^{k} y_{t+i}$, on $n x a_{t}$. Table 4 presents the results for horizons ranging from 1 to 24 quarters, for net total portfolio returns $\left(r_{t, k}\right)$ as well as net export growth $\left(\Delta n x_{t, k}\right)$. We postponed the discussion of the latter up to now because adjustment through the trade channel is likely to be taking place at horizons longer than one quarter. Note that the tables report results for two regressions, one regressing each $y_{t, k}$ on $n x a_{t}$ directly, and one regressing $y_{t, k}$ on the components of $n x a_{t}$, i.e. the cyclical components of exports, imports, gross assets and gross liabilities denoted $\epsilon_{t}^{x}, \epsilon_{t}^{m}, \epsilon_{t}^{a}, \epsilon_{t}^{l}$ respectively. The regression results vary little between the two versions of the regression.

\footnotetext{
${ }^{21}$ For simplicity, we use the regression without controls for this exercise. Adding controls makes virtually no difference, as already suggested by the results in Table 2.
} 
(a) dre

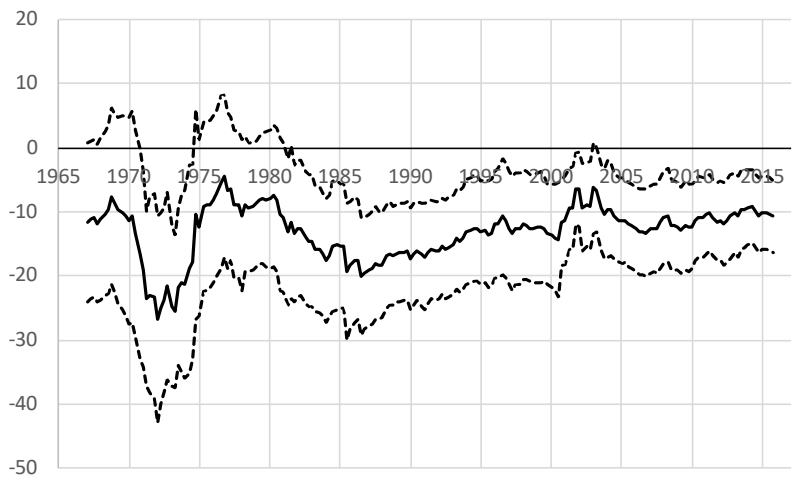

(c) $d r d$

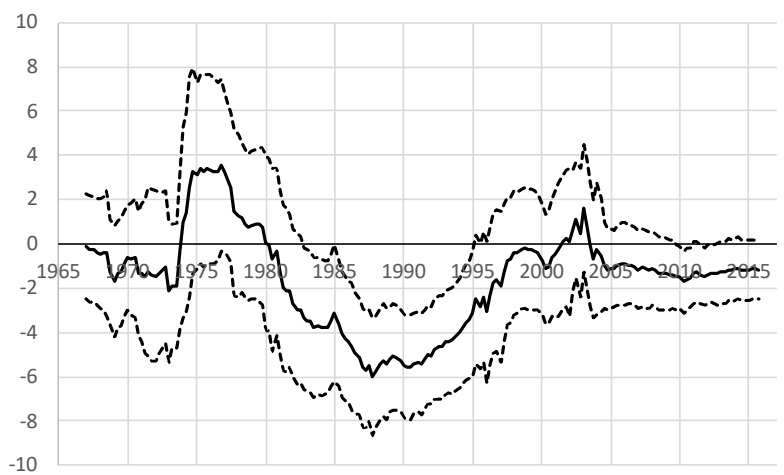

(e) $r$

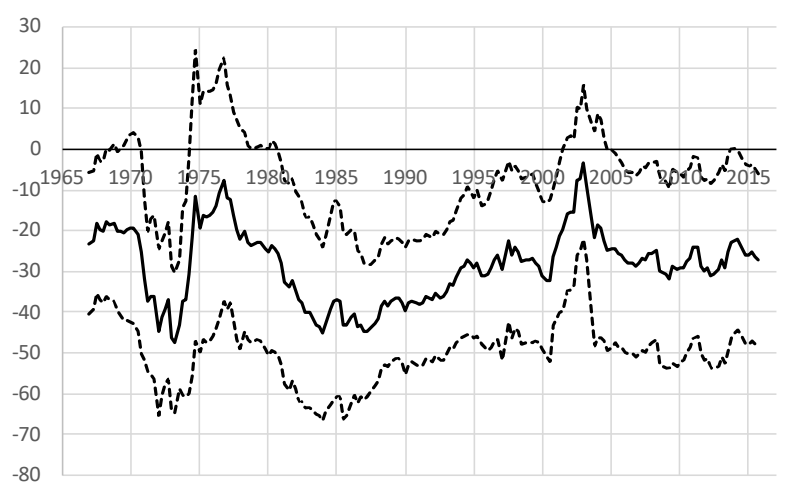

(b) $d r f$

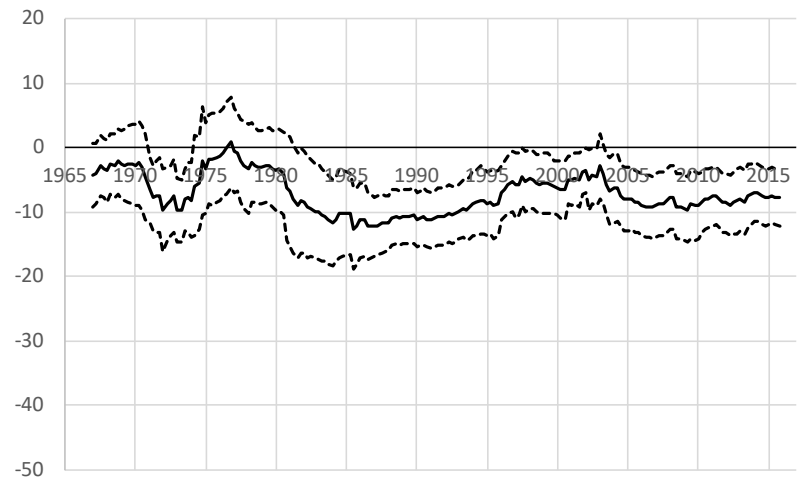

(d) $d r o$

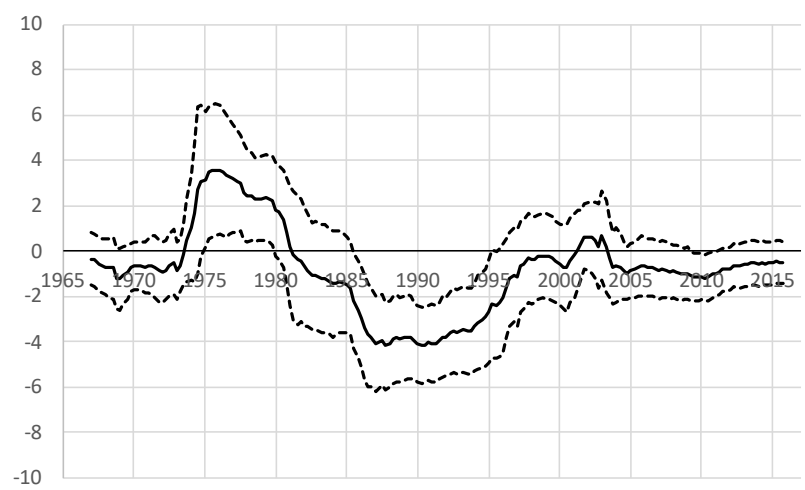

Figure 7: Rolling regressions equivalent of Table 3 . We run regressions of the form $y_{t+1}=$ $\alpha+\beta n x a_{t}+\epsilon_{t+1}$ on 15-year rolling windows. $y_{t+1}$ is the total real return on the net external position $\left(r_{t+1}\right)$, or return differentials for equity, FDI, debt, and other investment $\left(\Delta r_{t+1}^{i}=\right.$ $r_{t+1}^{a i}-r_{t+1}^{l i}$ for $\left.i \in\{e, f, d, o\}\right)$. Bands are $95 \%$ confidence intervals based on Newey-West standard-errors. The date is the end of each rolling window. All coefficients and standard errors are multiplied by 100 . 
Table 4: Long-horizon Regressions

\begin{tabular}{|c|c|c|c|c|c|c|c|c|}
\hline & \multicolumn{8}{|c|}{ Forecast Horizon (quarters) } \\
\hline & 1 & 2 & 3 & 4 & 8 & 12 & 16 & 24 \\
\hline & \multicolumn{8}{|c|}{ Panel A: Extended sample (1952Q1-2015Q4) } \\
\hline \multirow{3}{*}{$n x a$} & \multicolumn{8}{|c|}{ Real Total Net Portfolio Return $r_{t, k}$} \\
\hline & -26.31 & -26.88 & -27.26 & -26.28 & -18.94 & -14.07 & -11.30 & -4.85 \\
\hline & $(5.49)$ & $(5.20)$ & $(5.07)$ & (4.86) & (4.32) & (3.77) & (3.47) & $(2.52)$ \\
\hline $\bar{R}^{2}(1)$ & [0.08] & [0.14] & [0.21] & [0.24] & [0.24] & {$[0.20]$} & {$[0.18]$} & [0.06] \\
\hline \multirow[t]{2}{*}{$R^{2}(2)$} & [0.11] & {$[0.20]$} & [0.29] & [0.34] & [0.36] & [0.32] & [0.29] & [0.14] \\
\hline & \multicolumn{8}{|c|}{ Net Export growth $\Delta n x_{t, k}$} \\
\hline \multirow[t]{2}{*}{$n x a$} & -4.60 & -4.38 & -4.03 & -3.86 & -3.44 & -3.43 & -3.65 & -3.52 \\
\hline & $(1.70)$ & $(1.62)$ & (1.48) & $(1.34)$ & (1.01) & $(0.86)$ & $(0.71)$ & $(0.42)$ \\
\hline $\bar{R}^{2}(1)$ & [0.02] & [0.04] & [0.05] & [0.07] & {$[0.12]$} & [0.19] & [0.29] & [0.46] \\
\hline $\bar{R}^{2}(2)$ & [0.02] & {$[0.05]$} & {$[0.09]$} & {$[0.12]$} & [0.28] & [0.39] & [0.50] & [0.68] \\
\hline \multicolumn{9}{|c|}{ Panel B: Original sample (1952Q1-2004Q1) } \\
\hline \multirow{3}{*}{$n x a$} & \multicolumn{8}{|c|}{ Real Total Net Portfolio Return $r_{t, k}$} \\
\hline & -35.73 & -35.02 & -35.04 & -32.97 & -21.86 & -14.12 & -9.88 & -3.48 \\
\hline & $(7.26)$ & $(6.90)$ & (6.76) & $(6.60)$ & $(6.38)$ & $(5.26)$ & (4.66) & $(3.66)$ \\
\hline $\bar{R}^{2}(1)$ & [0.10] & [0.17] & {$[0.23]$} & [0.26] & [0.21] & {$[0.12]$} & [0.08] & [0.02] \\
\hline \multirow[t]{2}{*}{$\bar{R}^{2}(2)$} & [0.14] & [0.24] & [0.34] & {$[0.38]$} & [0.35] & [0.24] & [0.19] & [0.16] \\
\hline & \multicolumn{8}{|c|}{ Net Export growth $\Delta n x_{t, k}$} \\
\hline$n x a$ & -7.84 & -7.81 & -7.48 & -7.35 & -6.64 & -5.99 & -5.58 & -4.21 \\
\hline & $(2.26)$ & $(2.18)$ & (1.96) & $(1.72)$ & (1.04) & $(0.79)$ & $(0.65)$ & $(0.54)$ \\
\hline $\bar{R}^{2}(1)$ & [0.05] & [0.10] & [0.13] & [0.17] & [0.31] & [0.44] & [0.53] & [0.58] \\
\hline $\bar{R}^{2}(2)$ & [0.04] & [0.08] & [0.12] & [0.17] & [0.38] & [0.55] & [0.66] & [0.79] \\
\hline
\end{tabular}

Notes: Regressions of the form: $y_{t, k}=\alpha+\beta n x a_{t}+\epsilon_{t+k}$ where $y_{t, k}$ is the $k$-period real total net portfolio return $\left(r_{t, k}\right)$, or net export growth $\left(\Delta n x_{t, k}\right)$. Newey-West robust standard errors in parentheses with $k-1$ Bartlett window. Adjusted- $R^{2}$ in brackets. $\bar{R}(1)$ reports the adjusted- $R^{2}$ of the regression on $n x a_{t}$, while $\bar{R}(2)$ reports the adjusted- $R^{2}$ of the regression on $\epsilon_{t}^{x}, \epsilon_{t}^{m}, \epsilon_{t}^{a}$ and $\epsilon_{t}^{l}$, the stationary components of each variable. Boldface entries are significant at the 5 percent level. All coefficients and standard errors are multiplied by 100 . 
Table 4 shows that in-sample predictability for $r_{t, k}$ increases up to an adjusted- $R^{2}$ of $24 \%$ at four and eight-quarter horizons (34 and 36\% with separate regressors) before decreasing back to $6 \%(14 \%)$ at 24-quarter horizon. This confirms the findings of Gourinchas \& Rey (2007a), as seen in Panel B, that external adjustment through the financial channel operates at short to medium-term horizons (one quarter to two years).

The picture for net export growth is very different. A positive cyclical external imbalance predicts low future net export growth to restore equilibrium, which is consistent with Equation 2, but this channel is active at longer horizons. In the short to medium term, in-sample predictability is low, while it increases substantially as the horizon lengthens, culminating in an adjusted- $R^{2}$ of $46 \%$ at 24 quarters (68\% with separate regressors). Therefore, the standard trade channel of external adjustment is also present, but it operates at longer horizons.

In summary, our analysis illuminates the type of mechanisms through which the center country of the international monetary system adjusts to external imbalances. Unlike Hume's specie-flow there is no mechanical adjustment in gold reserves. Unlike the predictions of standard macroeconomic models, there is little evidence of adjustment via domestic macroeconomic policies that would shape future net exports, at least in the short to medium run. Instead, an increasing share of the adjustment takes place via predictable changes in the return on the US net foreign asset position. Adverse movements in the US net foreign asset positions predict positive future excess returns. These excess returns include (but are not limited to) convenience (liquidity or safety) yields on US external liabilities, relative to US external assets. ${ }^{22}$ The stabilizing role of these excess returns highlights the unique position that the U.S. continues to occupy at the center of the international financial system, and transcends any exchange rate regime arrangement in place since the early 1950s.

\section{The dollar exchange rate}

A natural question to investigate is the role of the dollar exchange rate in the adjustment mechanism, especially in the post Bretton Woods era of floating exchange rates. As discussed previously, the asymmetry in the currency composition of external assets and liabilities of the U.S. implies that movements in the dollar exchange rate mechanically affect the external balance. Are these dollar exchange rate fluctuations systematically tied to our measure of cyclical imbalances? We turn to this question in this section. Predicting nominal exchange rates is notoriously difficult, as has been shown for instance by Froot \& Rogoff $(1995)^{23}$. Our updated results re-affirm the findings of Gourinchas \& Rey (2007a) that cyclical external imbalances are good predictors of the dollar exchange rate: $n x a_{t}$ forecasts future exchange rate changes from one quarter ahead to long horizons (up to 24 quarters). We also compare our

\footnotetext{
${ }^{22}$ Because of the rapidly growing cross-border positions, in relation to the size of the economy over that period, even a small convenience yield can translate into substantial wealth transfers that alter the external adjustment dynamics.

${ }^{23}$ We focus mostly on in-sample predictability. In their classic paper, Meese \& Rogoff (1983) show that predicting exchange rate out-of-sample is particularly difficult. Indeed, very few models are able to beat the prediction of exchange rates following a simple random walk at short horizons. Gourinchas \& Rey (2007a) discuss the ability of $n x a_{t}$ to predict exchange rate changes out-of-sample, and show that it beats the random walk benchmark.
} 
results with the recent literature exploring the explanatory power of the convenience yield on US Treasuries for dollar exchange rates (see Jiang, Krishnamurthy \& Lustig (2018b)).

We begin by considering predictability at the one-quarter horizon. In Table 5, we run regressions of the form $y_{t+1}=\alpha+\beta n x a_{t}+\delta z_{t}+\epsilon_{t+1}$ with $y_{t+1}$ now being exchange rate changes. We use both a FDI-weighted measure $\left(\Delta e_{t+1}\right)$ and the Federal Reserve tradeweighted multilateral exchange rate for major currencies $\left(\Delta e_{t+1}^{T}\right)$. The sample covers the post-Bretton Woods period, from 1973Q1 to 2015Q4.

The results show that $n x a_{t}$ has a strong predictive power for both measures. The coefficient is negative and significant, which is consistent with positive cyclical external imbalances predicting a depreciation of the dollar one quarter ahead. The effect is economically substantial, with a one-standard-deviation decrease in $n x a_{t}(13.97 \%)$ predicting a 95 basis-point $(0.1397 \times 6.83 / 100)$ increase $(3.87$ percentage points in annualized terms $)$ in the expected rate of depreciation.

Table 5: Forecasting Quarterly Depreciation Rates

\begin{tabular}{|c|c|c|c|c|c|c|c|c|}
\hline \multirow[b]{3}{*}{$z_{t}:$} & \multicolumn{8}{|c|}{ Panel A: Extended sample (1952Q1-2015Q4) } \\
\hline & \multicolumn{4}{|c|}{ FDI-weighted $\left(\Delta e_{t+1}\right)$} & \multicolumn{4}{|c|}{ Trade-weighted $\left(\Delta e_{t+1}^{T}\right)$} \\
\hline & \multicolumn{2}{|c|}{$\Delta e_{t}$} & $x m_{t}$ & $i_{t}-i_{t}^{*}$ & \multicolumn{2}{|c|}{$\Delta e_{t}^{T}$} & $x m_{t-1}$ & $i_{t}-i_{t}^{*}$ \\
\hline$\hat{\beta}$ & -6.83 & -6.75 & -6.85 & -7.15 & -6.73 & -6.15 & -4.83 & -5.80 \\
\hline (s.e.) & $(1.59)$ & $(1.65)$ & $(2.90)$ & $(1.78)$ & $(1.84)$ & $(1.74)$ & $(2.46)$ & $(1.70)$ \\
\hline$\hat{\delta}$ & & 1.33 & 0.04 & 29.53 & & 10.84 & -3.51 & -84.46 \\
\hline (s.e.) & & $(6.80)$ & $(4.50)$ & $(31.36)$ & & $(6.80)$ & $(4.05)$ & $(33.25)$ \\
\hline $\bar{R}^{2}$ & 0.07 & 0.06 & 0.06 & 0.07 & 0.08 & 0.08 & 0.08 & 0.10 \\
\hline \multirow[t]{3}{*}{ \#obs } & 172 & 172 & 172 & 172 & 171 & 170 & 171 & 171 \\
\hline & \multicolumn{8}{|c|}{ Panel B: Original sample (1952Q1-2004Q1) } \\
\hline & \multicolumn{4}{|c|}{ FDI-weighted $\left(\Delta e_{t+1}\right)$} & \multicolumn{4}{|c|}{ Trade-weighted $\left(\Delta e_{t+1}^{T}\right)$} \\
\hline$z_{t}:$ & & $\Delta e_{t}$ & $x m_{t}$ & $i_{t}-i_{t}^{*}$ & & $\Delta e_{t}^{T}$ & $x m_{t-1}$ & $i_{t}-i_{t}^{*}$ \\
\hline$\hat{\beta}$ & -8.42 & -8.68 & -9.99 & -8.97 & -9.01 & -8.79 & -8.02 & -7.81 \\
\hline (s.e.) & $(1.95)$ & $(2.20)$ & (3.64) & $(2.30)$ & $(2.26)$ & $(2.34)$ & $(3.23)$ & (2.19) \\
\hline & & -3.69 & 2.35 & 31.79 & & 2.14 & -1.46 & -67.43 \\
\hline (s.e.) & & $(7.06)$ & $(5.49)$ & $(32.02)$ & & $(7.27)$ & $(5.46)$ & $(34.26)$ \\
\hline $\bar{R}^{2}$ & 0.09 & 0.08 & 0.08 & 0.08 & 0.11 & 0.10 & 0.10 & 0.13 \\
\hline \#obs & 125 & 124 & 125 & 125 & 124 & 123 & 124 & 124 \\
\hline
\end{tabular}

Notes: Regressions of the form: $y_{t+1}=\alpha+\beta n x a_{t}+\delta z_{t}+\epsilon_{t+1}$ where $y_{t+1}$ is the FDIweighted depreciation rate $\left(\Delta e_{t+1}\right)$, or the trade-weighted depreciation rate $\left(\Delta e_{t+1}^{T}\right) . x m_{t}$ is the stationary component from the trade balance, and $i_{t}-i_{t}^{*}$ is the short-term interest rate differential (in \%). Robust standard errors in parentheses. $\bar{R}^{2}$ is the adjusted- $R^{2}$. Boldface entries are significant at the 5 percent level. All coefficients and standard errors are multiplied by 100 .

Several aspects are noteworthy. First, $n x a_{t}$ does particularly well even at relatively short horizons. This is noteworthy, given the typical difficulty in predicting exchange rates in standard empirical models. In that respect, the adjusted- $R^{2}$ are quite high (around 7 to 10\%). 
Second, adding control variables such as the interest rate differential or lags, makes little difference. Third, when comparing results with those of the original sample of Gourinchas \& Rey (2007a), the stability of the relationship is quite remarkable given that the Great Financial Crisis of 2008 and the euro area sovereign debt crisis are now included in the sample.

Let us turn to longer horizons. Table 6 presents the same predictability results but for horizons ranging between 1 and 24 quarters. In-sample predictability increases with the horizon, with adjusted- $R^{2}$ reaching an impressive $52 \% 12$ quarters ahead $(60 \% 16$ quarters ahead if we use separate $\epsilon^{z}$ s as regressors). In other words, $n x a_{t}$ is able to predict in-sample exchange-rate changes in the short, medium, and long term. This suggests that two dynamics are at play. In the short to medium term, valuation effects are the main adjustment channels and exchange rate changes participate by impacting the return on the net external portfolio. In the medium to long term, the valuation channel is mostly inactive and returns are not predictable. However, the trade channel of adjustment becomes more relevant. We hypothesize that exchange rate changes remain predictable precisely because of their role for trade flows at longer horizons.

Table 6: Long-horizon Regressions

\begin{tabular}{|c|c|c|c|c|c|c|c|c|}
\hline & \multicolumn{8}{|c|}{ Forecast Horizon (quarters) } \\
\hline & 1 & 2 & 3 & 4 & 8 & 12 & 16 & 24 \\
\hline & \multicolumn{8}{|c|}{ FDI-weighted effective nominal rate of depreciation $\Delta e_{t, k}$} \\
\hline & \multicolumn{8}{|c|}{ Panel A: Extended sample (1952Q1-2015Q4) } \\
\hline \multirow[t]{2}{*}{$n x a$} & & -6.94 & -6.93 & -6.71 & -6.44 & -5.56 & -4.64 & -2.55 \\
\hline & & $(1.50)$ & $(1.40)$ & $(1.31)$ & $(1.00)$ & $(0.81)$ & $(0.71)$ & $(0.67)$ \\
\hline $\bar{R}^{2}(1)$ & {$[0.07]$} & {$[0.1$} & [0.23] & {$[0.28]$} & [0.47] & {$[0.52]$} & [0.48] & {$[0.23]$} \\
\hline \multirow[t]{2}{*}{$\bar{R}^{2}(2)$} & {$[0.06]$} & {$[0.14]$} & {$[0.23]$} & {$[0.29]$} & {$[0.49]$} & {$[0.59]$} & {$[0.60]$} & {$[0.41]$} \\
\hline & \multicolumn{8}{|c|}{ Panel B: Original sample (1952Q1-2004Q1) } \\
\hline$n x a$ & 42 & -8.16 & -8.09 & -7.80 & -6.96 & & -4.20 & -1. \\
\hline & & & $(1.75)$ & (1.64) & $(1.40)$ & & & $(1.00)$ \\
\hline $\bar{R}^{2}(1)$ & {$[0.09]$} & {$[0.16]$} & {$[0.27]$} & {$[0.31]$} & {$[0.41]$} & {$[0.41]$} & {$[0.3$} & {$[0.12]$} \\
\hline $\bar{R}^{2}(2)$ & {$[0.10]$} & {$[0.21]$} & {$[0.35]$} & {$[0.40]$} & {$[0.52]$} & {$[0.55]$} & {$[0.55]$} & {$[0.38]$} \\
\hline
\end{tabular}

Notes: Regressions of the form: $y_{t, k}=\alpha+\beta n x a_{t}+\epsilon_{t+k}$ where $y_{t, k}$ is the $k$-period FDIweighted depreciation rate $\left(\Delta e_{t, k}\right)$. Newey-West robust standard errors in parentheses with $k-1$ Bartlett window. Adjusted- $R^{2}$ in brackets. $\bar{R}(1)$ reports the adjusted- $R^{2}$ of the regression on $n x a_{t} ; \bar{R}(2)$ reports the adjusted- $R^{2}$ of the regression on $\epsilon_{t}^{x}, \epsilon_{t}^{m}, \epsilon_{t}^{a}$ and $\epsilon_{t}^{l}$, the stationary components of each variable. The sample is 1973Q1-2015Q4. Boldface entries are significant at the 5 percent level. All coefficients and standard errors are multiplied by 100 .

The most vivid way to visualize the predictive power of cyclical external imbalances for exchange rate changes is to look at Figure 8, which plots the FDI-weighted nominal effective depreciation rate from one to 12 quarter ahead against its fitted values using $n x a_{t}$, and independently with $\epsilon^{z}$ as regressors. The increase in predictive power as the horizon grows is particularly striking. The plot also emphasizes that the $n x a_{t}$ variable is able to pick up 

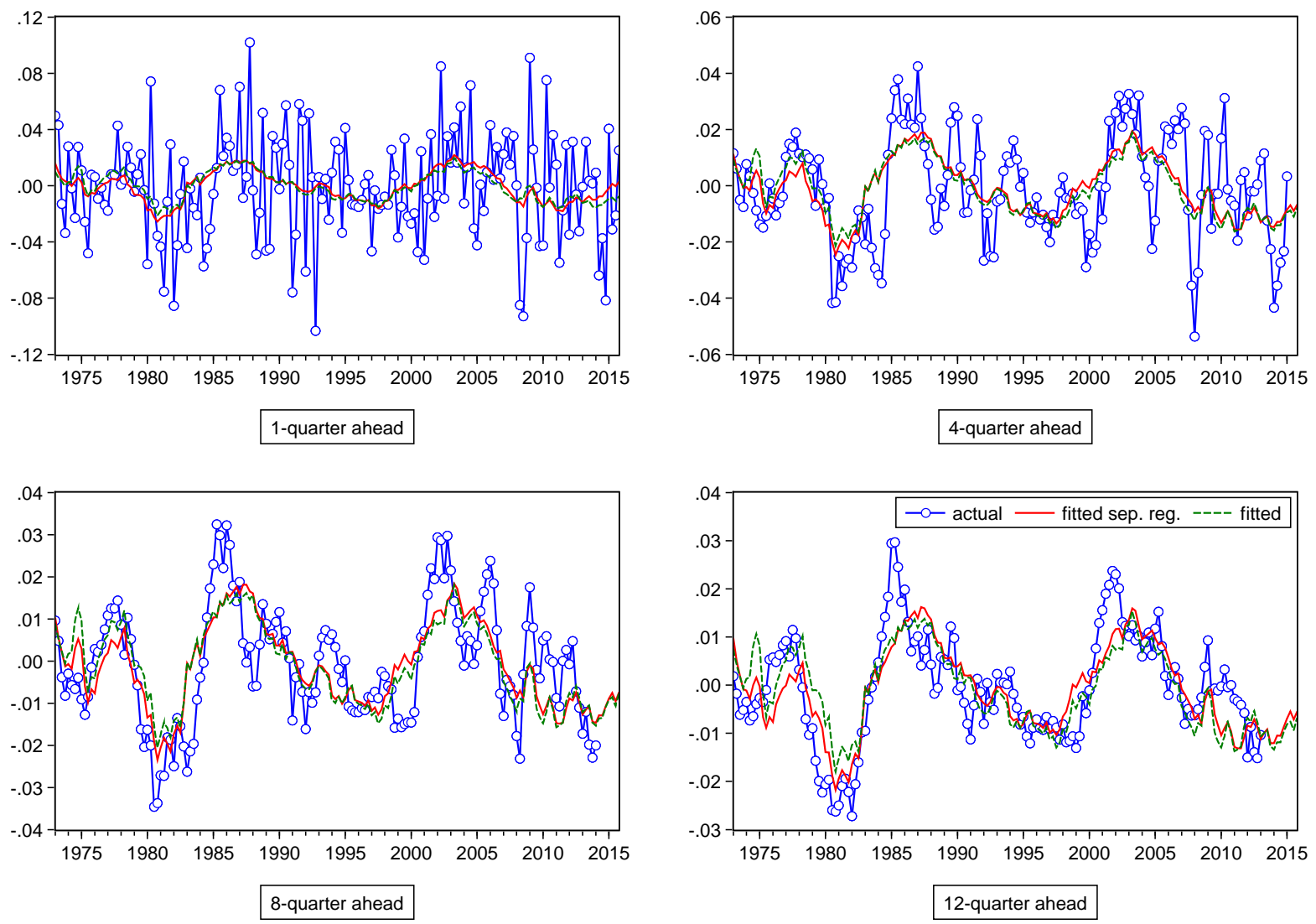

Figure 8: Predicted 1 to 12-quarter ahead depreciation rates. Each graph reports (a) the realized depreciation rate at the 1 to 12-quarter horizon, (b) the fitted depreciation rate using nxa (fitted), and (c) the fitted depreciation rate using $\epsilon^{x}, \epsilon^{m}, \epsilon^{a}$ and $\epsilon^{l}$, as separate regressors (fitted sep. reg.).

both the general tendencies in exchange rate changes and their turning points.

We now turn to a comparison with the results of Jiang, Krishnamurthy \& Lustig (2018b), who also emphasize the specific features of dollar assets in the international financial system. In that paper, the authors propose a theory of dollar exchange rate determination based on the convenience yields offered by US safe securities. Specifically, US Treasuries and US deposits offering the LIBOR rate provide a convenience yield to investors both in the United States and abroad. This convenience yield measures the non-pecuniary value that investors impute to the safety and liquidity properties of US safe assets (cf. also Krishnamurthy \& Vissing-Jorgensen , 2012). When an episode of global financial instability occurs, the flight to the safety and liquidity of US securities drives up their convenience yield. A transitory flight to safety results in a surge in demand for US assets, and is reflected in a contemporaneous appreciation of the US dollar, followed by an expected depreciation over subsequent periods. That theory suggests that movements in convenience yields can predict movements in the dollar exchange rate. In a recent paper, Engel \& Wu (2019) also explore the link 
between liquidity yield and exchange rate movements and conclude that liquidity yields are an important determinant of exchange rates for all the G-10 countries.

In what follows, we compare the information contained in convenience yields constructed by Jiang, Krishnamurthy \& Lustig (2018b) and in our measure of cyclical imbalances $n x a_{t}$ for the dollar exchange rate predictability. Jiang, Krishnamurthy \& Lustig (2018b) proxy the convenience yield with the Treasury basis, i.e. the yield difference between on-shore and off-shore Treasuries of identical maturity, denoted $x_{t}^{\text {Treas }}$. The predictability of $n x a_{t}$ for excess returns (the valuation channel of adjustment) is consistent with, but is not limited to, the existence of a convenience yield on US external liabilities relative to US external assets, both broadly defined. Our approach does not take a specific stance on which asset-pair, if any, will exhibit an excess return in equilibrium. More broadly, it captures the equilibrium global banker and insurer functions of the hegemon. For instance, our approach is valid whether on-shore Treasuries are cheaper than off-shore ones (the convenience yield of Jiang, Krishnamurthy \& Lustig (2018b)) or whether the excess return manifests itself in the asymmetric composition of the external balance sheet, with more risky assets on the asset side and more safe liabilities on the liability side. ${ }^{24}$

We adopt an empirical specification similar to Jiang, Krishnamurthy \& Lustig (2018b) and regress the rate of depreciation of the dollar on the Treasury and LIBOR bases, $x_{t}^{\text {Treas }}$ and $x_{t}^{\mathrm{LIBOR}}$, respectively, alongside $n x a_{t} \cdot{ }^{25}$ In their paper, and our results below, the basis is defined such that a decrease corresponds to an increase in convenience yields and should be associated with an immediate appreciation of the dollar exchange rate, followed by a subsequent depreciation. ${ }^{26}$ We run both univariate predictability regressions, in which exchange rate changes are regressed on each measure separately, and multivariate ones, in which we include all variables as regressors. ${ }^{27}$ Results are presented in Table $7 .^{28}$

\footnotetext{
${ }^{24}$ See Gourinchas \& Rey (2007b) for an early discussion of within and between excess returns on the US external balance sheet.

${ }^{25} \mathrm{As}$ in that paper, we also add the innovations to change in the bases, obtained as the residual $\varepsilon_{t}^{\text {Treas }}$ from the following regression: $x_{t}^{\text {Treas }}-x_{t-1}^{\text {Treas }}=\alpha+\beta_{1}\left(i_{t-1}^{\Phi}-i_{t-1}^{*}\right)+\beta_{2} x_{t-1}^{\text {Treas }}+\varepsilon_{t}^{\text {Treas }}$. Innovations to the LIBOR basis are obtained in a similar fashion.

${ }^{26}$ The only additional difference with previous regressions is that the sample is now limited to 1988Q1 to 2015Q4 due to the availability of the basis measures.

${ }^{27}$ Note that for "univariate" regressions, the innovations to $\Delta x_{t}$ and $\Delta x_{t-1}$ are always included as controls alongside the basis in level. As suggested in Jiang, Krishnamurthy \& Lustig (2018b), we also run the univariate regressions using the interest rate differential $d i_{t}$ both as independent regressor and as control. Results are mostly unaffected and these are omitted in the interest of space. We keep the interest rate differential as a control in the multivariate regressions.

${ }^{28}$ We use the FDI-based exchange rate measure extended from Gourinchas \& Rey (2007a). Results are similar if we use the measure from Jiang, Krishnamurthy \& Lustig (2018b), although the basis measure has a stronger predictive power at the 3-year horizon (roughly on par with $n x a_{t}$ ). Those results are reported in Table A1 of the Appendix. In addition, the weights for the $n x a_{t}$ measure are based on the full extended sample (1952Q1-2015Q4), but results are unchanged if we re-estimate them on the limited sample (1988Q12015Q4).
} 
Table 7: Predictability at several horizons with $\mathbf{n x a}_{\mathbf{t}}$ and basis measures of Jiang, Krishnamurthy \& Lustig (2018b)

\begin{tabular}{|c|c|c|c|c|c|c|c|c|c|}
\hline & \multicolumn{8}{|c|}{ Forecast Horizon (quarters) } \\
\hline & & 1 & 2 & 3 & 4 & 8 & 12 & 16 & 24 \\
\hline \multicolumn{10}{|c|}{ Panel A: Univariate regressions } \\
\hline \multirow[t]{3}{*}{$n x a_{t}$} & coef. & -5.22 & -5.64 & -6.03 & -5.82 & -5.96 & -4.92 & -4.50 & -3.13 \\
\hline & p-value & $(0.03)$ & $(0.01)$ & $(0.00)$ & $(0.00)$ & $(0.00)$ & $(0.00)$ & $(0.00)$ & $(0.00)$ \\
\hline & $\operatorname{adj.}-R^{2}$ & {$[0.02]$} & {$[0.07]$} & {$[0.14]$} & {$[0.18]$} & {$[0.43]$} & {$[0.51]$} & {$[0.56]$} & {$[0.37]$} \\
\hline \multirow[t]{3}{*}{$x_{t}^{\text {Treas }}$} & coef. & 7.41 & 5.48 & 1.46 & -0.99 & -0.74 & -1.59 & -1.36 & -0.79 \\
\hline & p-value & $(0.06)$ & $(0.06)$ & $(0.60)$ & $(0.71)$ & $(0.65)$ & $(0.25)$ & $(0.30)$ & $(0.47)$ \\
\hline & $\operatorname{adj} .-R^{2}$ & {$[0.04]$} & {$[0.00]$} & {$[-0.02]$} & {$[-0.01]$} & {$[-0.03]$} & {$[-0.01]$} & {$[-0.01]$} & {$[-0.02]$} \\
\hline \multirow[t]{3}{*}{$\Delta x_{t}^{\text {Treas }}$} & coef. & -4.80 & -5.54 & -0.82 & 2.02 & 0.90 & 1.73 & 1.44 & 0.68 \\
\hline & p-value & $(0.26)$ & $(0.06)$ & $(0.79)$ & $(0.47)$ & $(0.56)$ & $(0.20)$ & $(0.22)$ & $(0.52)$ \\
\hline & $\operatorname{adj} .-R^{2}$ & {$[0.04]$} & {$[0.00]$} & {$[-0.02]$} & {$[-0.01]$} & {$[-0.03]$} & {$[-0.01]$} & {$[-0.01]$} & {$[-0.02]$} \\
\hline \multirow[t]{3}{*}{$\Delta x_{t-1}^{\text {Treas }}$} & coef. & -6.60 & -3.40 & -0.34 & 0.74 & 0.13 & 0.52 & 0.45 & 0.16 \\
\hline & p-value & $(0.00)$ & $(0.09)$ & $(0.86)$ & $(0.60)$ & $(0.88)$ & $(0.41)$ & $(0.34)$ & $(0.75)$ \\
\hline & $\operatorname{adj} .-R^{2}$ & {$[0.04]$} & {$[0.00]$} & {$[-0.02]$} & {$[-0.01]$} & {$[-0.03]$} & {$[-0.01]$} & {$[-0.01]$} & {$[-0.02]$} \\
\hline \multirow[t]{3}{*}{$x_{t}^{\mathrm{LIBOR}}$} & coef. & 2.39 & -2.55 & -1.89 & -1.44 & 0.80 & 2.31 & 0.72 & 2.82 \\
\hline & p-value & $(0.65)$ & $(0.52)$ & $(0.61)$ & $(0.66)$ & $(0.75)$ & $(0.30)$ & $(0.70)$ & $(0.07)$ \\
\hline & $\operatorname{adj} .-R^{2}$ & {$[0.02]$} & {$[-0.01]$} & {$[-0.01]$} & {$[-0.03]$} & {$[-0.02]$} & {$[0.00]$} & {$[-0.01]$} & {$[0.03]$} \\
\hline \multirow[t]{3}{*}{$\Delta x_{t}^{\mathrm{LIBOR}}$} & coef. & 2.39 & 4.10 & 2.73 & 1.78 & -0.81 & -1.99 & -0.15 & -2.60 \\
\hline & p-value & $(0.69)$ & $(0.36)$ & $(0.48)$ & $(0.60)$ & $(0.75)$ & $(0.37)$ & $(0.94)$ & $(0.10)$ \\
\hline & $\operatorname{adj} .-R^{2}$ & {$[0.02]$} & {$[-0.01]$} & {$[-0.01]$} & {$[-0.03]$} & {$[-0.02]$} & {$[0.00]$} & {$[-0.01]$} & {$[0.03]$} \\
\hline \multirow[t]{3}{*}{$\Delta x_{t-1}^{\mathrm{LIBOR}}$} & coef. & -2.62 & 0.25 & -0.20 & 0.48 & -1.06 & -1.04 & -0.15 & -1.36 \\
\hline & p-value & $(0.47)$ & $(0.93)$ & $(0.93)$ & $(0.77)$ & $(0.42)$ & $(0.32)$ & $(0.88)$ & $(0.09)$ \\
\hline & $\operatorname{adj} .-R^{2}$ & {$[0.02]$} & {$[-0.01]$} & {$[-0.01]$} & {$[-0.03]$} & {$[-0.02]$} & {$[0.00]$} & {$[-0.01]$} & {$[0.03]$} \\
\hline \multicolumn{10}{|c|}{ Panel B: Multivariate regressions } \\
\hline \multirow[t]{2}{*}{$n x a_{t}$} & coef. & -6.20 & -6.69 & -7.06 & -6.88 & -6.57 & -5.28 & -4.72 & -3.49 \\
\hline & p-value & $(0.01)$ & $(0.00)$ & $(0.00)$ & $(0.00)$ & $(0.00)$ & $(0.00)$ & $(0.00)$ & $(0.00)$ \\
\hline \multirow[t]{2}{*}{$x_{t}^{\text {Treas }}$} & coef. & 9.95 & 7.89 & 1.82 & -0.81 & -1.24 & -2.18 & -1.54 & -1.76 \\
\hline & p-value & $(0.03)$ & $(0.01)$ & $(0.47)$ & $(0.76)$ & $(0.30)$ & $(0.02)$ & $(0.09)$ & $(0.05)$ \\
\hline \multirow[t]{2}{*}{$x_{t}^{\mathrm{LIBOR}}$} & coef. & -3.02 & -5.91 & -1.89 & -0.87 & 0.59 & 1.99 & 0.59 & 3.34 \\
\hline & p-value & $(0.63)$ & $(0.16)$ & $(0.57)$ & $(0.76)$ & $(0.72)$ & $(0.17)$ & $(0.62)$ & $(0.01)$ \\
\hline \multirow[t]{2}{*}{$\Delta x_{t}^{\text {Treas }}$} & coef. & -8.06 & -7.80 & -0.67 & 2.80 & 2.00 & 2.69 & 1.64 & 1.60 \\
\hline & p-value & $(0.13)$ & $(0.03)$ & $(0.83)$ & $(0.33)$ & $(0.10)$ & $(0.01)$ & $(0.07)$ & $(0.08)$ \\
\hline \multirow[t]{2}{*}{$\Delta x_{t}^{\mathrm{LIBOR}}$} & coef. & 5.82 & 7.19 & 1.70 & -0.68 & -1.65 & -2.63 & -0.64 & -3.24 \\
\hline & p-value & $(0.45)$ & $(0.15)$ & $(0.64)$ & $(0.82)$ & $(0.38)$ & $(0.10)$ & $(0.61)$ & $(0.02)$ \\
\hline \multirow[t]{2}{*}{$\Delta x_{t-1}^{\text {Treas }}$} & coef. & -7.87 & -3.86 & 0.94 & 1.33 & 1.15 & 1.19 & 0.68 & 0.80 \\
\hline & p-value & $(0.03)$ & $(0.10)$ & $(0.59)$ & $(0.42)$ & $(0.11)$ & $(0.04)$ & $(0.12)$ & $(0.11)$ \\
\hline \multirow[t]{3}{*}{$\Delta x_{t-1}^{\mathrm{LIBOR}}$} & coef. & 2.97 & 2.49 & -1.48 & -0.60 & -1.66 & -1.37 & -0.35 & -1.66 \\
\hline & p-value & $(0.51)$ & $(0.36)$ & $(0.45)$ & $(0.72)$ & $(0.17)$ & $(0.11)$ & $(0.58)$ & $(0.02)$ \\
\hline & $\operatorname{adj} .-R^{2}$ & {$[0.07]$} & {$[0.12]$} & {$[0.17]$} & {$[0.21]$} & {$[0.47]$} & {$[0.57]$} & {$[0.59]$} & {$[0.50]$} \\
\hline
\end{tabular}

Notes: Cf. below. 
Notes for Table \%: The dependent variable is the FDI-weighted depreciation rate, $\Delta e_{t, k}=$ $e_{t+k}-e_{t}$, extended from Gourinchas \& Rey (2007a). Sample: 1988Q1-2015Q4. nxa weights are computed on the full sample (1952Q1-2015Q4). Panel A presents the results for univariate regressions of the form $\Delta e_{t, k}=\alpha+\beta v+\epsilon_{t}$ with $v \in\left\{n x a_{t}, x_{t}^{\text {Treas }}, x_{t}^{\text {LIBOR }}, d i_{t}\right\}$. For Panel A regressions on each $x_{t}$, the corresponding $\Delta x_{t}$ and $\Delta x_{t-1}$ are also included as controls. Panel $\mathrm{B}$ presents the results for multivariate regressions of $\Delta e_{t, k}$ on all variables together, also controlling for interest rate differential. Standard-errors are computed using Newey-West with Bartlett windows of $k-1$ quarters, and p-values reported in parentheses. Boldface entries are significant at the 5 percent level. All coefficients are multiplied by 100 , and basis measures are expressed in percentage points to make the magnitude of the coefficients broadly comparable (in terms of the effect of a 1-standard deviation change).

We focus first on the univariate regressions. For short horizons, one to two quarters ahead, $n x a_{t}$ and the US Treasury basis $x_{t}^{\text {Treas }}$ are significant at the $5 \%$ and $10 \%$ level respectively, and the coefficient are of similar magnitude. Note that the coefficient on the basis measure is positive, i.e. a higher convenience yield (associated with a lower basis) is associated with a subsequent appreciation of the dollar exchange rate, not a depreciation. These results are consistent with the authors' own findings, which they attribute to momentum in currency markets. Similarly, an increase in $n x a_{t}$ corresponds to a future appreciation of the dollar exchange rate, delivering negative excess returns, also as suggested by theory. Both effects are economically large: a one-standard-deviation lower basis $(0.2482 \%)$ predicts an annualized 7.56 percentage-point decrease in the depreciation rate one quarter ahead (5.55 percentage points two quarters ahead), while a one-standard-deviation decrease in $n x a_{t}(13.97 \%)$ predicts an annualized 2.95 percentage-point increase one quarter ahead (3.19 percentage-point two quarters ahead). At one quarter, both variables do roughly as well in terms of adjusted- $R^{2}$ ( $4 \%$ for $x_{t}^{\text {Treas }}$ vs. $2 \%$ for $n x a_{t}$ ), but from two quarter ahead onwards, the adjusted- $R^{2}$ for $n x a_{t}$ becomes significantly larger. The LIBOR basis does not do as well, with the coefficient being smaller and insignificant. This is also documented in Jiang, Krishnamurthy \& Lustig (2018a), who show that the LIBOR basis helps mostly on the most recent part of the sample, after the Great Recession. Finally, note that, the effect of the innovations to the Treasury basis measure $\Delta x^{\text {Treas }}$ have roughly the same magnitudes, albeit with a flipped sign and varying significance levels. Innovations to the LIBOR basis are mostly insignificant.

As the horizon extends, the picture changes. First, the coefficient on the Treasury basis changes sign, as in Jiang, Krishnamurthy \& Lustig (2018b), so that it now becomes consistent with the authors' prediction: an increase in convenience yield is associated with a dollar depreciation in the future. However, in the univariate regressions, the predictive power of the basis measures decreases sharply, with very small adjusted- $R^{2}$. Using the exchange rate measure from Jiang, Krishnamurthy \& Lustig (2018b) as in Table A1 does not alter the results, except at the 3-year horizon for which the coefficient on $x_{t}^{\text {Treas }}$ becomes larger (roughly on par with $\left.n x a_{t}\right)$ and significant $(\mathrm{p}$-value $=2 \%)$. By contrast, the predictive power of $n x a_{t}$ grows strongly with the horizon, with coefficients staying broadly stable. This is the case for both measures of exchange rate changes.

The results from the multivariate regressions also prove informative. Interestingly, using both $n x a_{t}$ and the basis in the regression appears to help $x_{t}^{\text {Treas }}$ achieve stronger significance, and slightly larger coefficients. At the 12-quarter horizon, a one standard-deviation lower 
basis $(0.2482 \%)$ does predict an annualized 2.18-percentage-point increase in the depreciation rate, with a p-value of $2 \%$, vs. an annualized 2.98-percentage-point increase for a onestandard-deviation decrease in $n x a_{t}$ (p-value $\approx 0 \%$ ). At long-term horizons (16 and 24 quarters), $x_{t}^{\text {Treas }}$ remains significant (p-value of $9 \%$ and $5 \%$ respectively), but with coefficients becoming significantly smaller. The coefficient for $n x a_{t}$ remains broadly stable from one to 24 quarter ahead, and always strongly significant ( $\mathrm{p}$-value $\approx 0 \%$ for all horizons).

Taken together, those results suggest that $x_{t}^{\text {Treas }}$ and $n x a_{t}$ capture complementary channels: a flight-to-safety channel for convenience yields, and a broader valuation channel including a convenience yield for $n x a_{t}$. Combining the two measures leads to striking predictive power at all horizons, with adjusted- $R^{2}$ ranging from $7 \%$ to $59 \%$. Documenting this complementarity further is an interesting avenue that we leave for future research. Second, controlling for additional variables, such as the interest rate differential, makes little difference. Third, the fact that $n x a_{t}$ stays important at most horizons, even when controlling for basis measures and other variables, suggests that it captures more than just the short-term demand for safe assets. Indeed, this emphasizes that $n x a_{t}$ also includes cyclical adjustments through trade, as well as valuation effects on other assets such as equity and FDI, and that those are also important in predicting exchange rates. This is consistent for instance with the last leg of the portfolio rebalancing model developed and tested in Hau \& Rey (2004, 2006) and Camanho, Hau \& Rey (2018). In this model, return changes on assets held in other countries, in particular equities, lead to a change in currency exposure that investors want to counterbalance. This leads to portfolio rebalancing, which in turn affects the exchange rate.

\section{$5 \quad$ Exorbitant privilege}

The country at the centre of the international monetary system, the hegemon, issues the dominant currency. There are important inter-related functions of international currencies in good and asset markets. The implications of the process of international adjustment for the hegemon depends on the rules of the games of the international monetary system. Under Bretton Woods, dollar balances were held abroad to perform international payments. In our fiat currency system, being the hegemon confers a specific ability to issue large amount of nominally safe liabilities (dollar securities) which are happily absorbed by the rest of the world. Hence the view that in case of a deficit, the United States do not have to take restrictive measures, so that the dollar is not an impartial means of international exchange. This is the essence of the "exorbitant privilege". Different aspects of this "exorbitant privilege" have been characterised in different ways by a series of papers in the literature. Gourinchas \& Rey (2007b) constructs estimates of external assets and liabilities of the United States at market value at the quarterly frequency for the entire post-war period. They emphasize that the characteristics of its balance sheet make the US akin to a "world banker" or even a "world venture capitalist" due to the asymmetry between risky assets and safe liquid liabilities. They compute the first estimates of the excess returns on the US net foreign asset position $^{29}$ : these are sizable, around $2 \%$ per year in real terms. Those excess returns and the associated valuation channel of adjustment (see Gourinchas \& Rey (2007a) and section

\footnotetext{
${ }^{29}$ See also Lane \& Milesi-Ferretti (2009) and Curcuru, Dvorak \& Warnock (2008).
} 
3) ease the process of external adjustment for the US. This is precisely what Gourinchas \& Rey (2007b) calls "the exorbitant privilege". Gourinchas, Rey \& Govillot (2017) go a lot further. They derive the external balance sheet of the US as an optimizing problem in general equilibrium when the US has a comparative advantage in risk taking. The key assumption is that the US is less risk averse as a country than the rest of the world. Maggiori (2017) shows that this asymmetry in risk aversion can be microfounded from differences in degrees of frictions in capital markets in the US versus the world. In his model, a tighter constraint in the banking system of the rest of the world looks like a higher aggregate degree of risk aversion of the rest of the world ${ }^{30}$. Maggiori (2017) derives the implications of these financial imperfections on external asset positions while Gourinchas, Rey \& Govillot

(2017) draw the implications of their risk-sharing model. In global crisis times, the U.S., less risk-averse, insures the rest of the world, which receives a substantial wealth transfer. The value of the risky external assets of the U.S. collapses while the value of its liabilities (mostly reserve assets) goes up and an insurance transfer is made from the US to the rest of the world ${ }^{31}$. Therefore, in Gourinchas, Rey \& Govillot (2017), the U.S. is the world insurer and the "exorbitant privilege" is an insurance fee being paid in normal times in exchange for an insurance transfer - "the exorbitant duty" - being implemented in global crisis times via the structure of the external portfolio of the United States.

In contrast, Farhi \& Maggiori (2018) interprets the "exorbitant privilege" as a monopoly rent that the US can extract as the sole issuer of the international currency ${ }^{32}$. In their model, the centre country is the sole issuer of reserve assets demanded by the rest of the world and it faces a commitment problem. Ex-post, in bad states of the world, the hegemon faces a trade-off between inflating away the debt to limit real repayments or incurring the cost of default. Ex-ante, the centre country chooses how much debt to issue before interest rates are determined. This allows for the possibility of self-fulfilling confidence crises à la Calvo (1988) where the hegemon depreciates its currency when expectations of investors are adverse. In their setting, the hegemon obtains monopoly rents in the form of a positive endogenous safety premium on reserve assets. He, Krishnamurthy \& Milbradt (2019) investigate why US debt appears to have high valuations relative to the debt of other countries with similar fundamentals (see also Krishnamurthy \& Vissing-Jorgensen $(2011,2012)$ and Hassan (2013)). He, Krishnamurthy \& Milbradt (2019) interpret the safety property of a reserve currency as the result of a coordination game of investors buying that currency and propping up its value. In their model, for a country's bond to be safe, the number of investors who invest in the bond must exceed a threshold, which is decreasing in the country's fundamentals and increasing in the size of the debt. Hence, the safety of an asset and the "exorbitant privilege" are linked to the complementarities in the strategy of investors. In a model with complementarities between invoicing and banking, Gopinath \& Stein (2018a) interpret the deviation of interest rate parity due to the large demand for dollars as an "exorbitant privilege". Finally, several authors, e.g. Maggiori, Neiman \& Schreger (2018), have emphasized the specific liquidity

\footnotetext{
${ }^{30}$ Another possible microfoundation can be found in Mendoza, Quadrini \& Ríos-Rull (2009), where it is a better ability to share idiosyncratic risk within the US, which enables the US to be long in risky assets internationally.

${ }^{31}$ For a detailed empirical analysis of bilateral gains and losses during the 2008 financial crisis, see Gourinchas, Rey \& Truempler (2012).

${ }^{32}$ Farhi \& Maggiori (2018) also considers the oligopolistic case of several suppliers of the reserve assets and study its stability.
} 
properties of US dollar bond markets, which enable easier access to funds for corporations - even including small companies- issuing in dollars. All those represent some facets of the "exorbitant privilege" enjoyed by the hegemon.

\section{The new Triffin dilemma}

Observers of the Gold Standard and Bretton Woods systems have for a long time noted the tension between the international liquidity provision function of the hegemon and the net asset position backing the gold-like liquidity being issued. Triffin (1961) pointed out that for the US to issue enough reserve assets to lubricate payment adjustment, it must run balance of payments deficits under official settlements as it accumulates liabilities to foreign officials without increasing official assets like gold. In a context where the dollar value was fixed against gold, this could decrease foreign confidence in the dollar and there would be an unavoidable run on the dollar. If on the contrary the U.S. were to limit its provision of liquid reserve assets to the world, as the world economy grew, so would liquidity demand and there would be a shortage of reserve assets, which would impede international transactions. This is the "Triffin dilemma". ${ }^{33}$ Addressing this issue, Kenen (1960) wrote a formal model of the dynamics of the balance of payments of the reserve currency country in the context of the gold standard when new gold production is not enough to satisfy the increase in world liquidity demand. He shows that the system can become unstable especially in a context where there are swift increases of private dollar holdings abroad. Despres, Kindleberger \& Salant (1966), labeling themselves as "the minority view" given the influence of the position of Triffin at the time, questioned the unavoidability of a run on the dollar and emphasized the role of the U.S. as a financial intermediary in a world where US markets had more breadth and liquidity than European ones. They argued that there is nothing ominous in the balance of payments deficits of the US as these reflects the activity of a "world banker" lending long term and borrowing short term just like New York banks lent to the rest of the United States. They dismissed the possibility of a run on the dollar as reflecting purely the nervousness of some Central Bankers and academic economists. As should be clear from the above description and has been noted e.g. in Portes (2012) and Bordo \& McCauley (2018), the Triffin dilemma has nothing to do with the current account deficits of the US (those are net flows). Fundamentally, the Triffin dilemma is about the magnitude of the gross stock of liquid dollar liabilities held abroad (necessary to lubricate the international payment system) and the possible loss of confidence in the value of the dollar by foreign investors, whether due to policies, sentiment, or fundamentals (e.g. relative size of the hegemon in the world economy). This is the reason why the Triffin dilemma has not lost its relevance, even in an international monetary system that lacks a formal anchor.

\section{Gourinchas \& Rey (2007b) write:}

"Triffin saw that in a world where the fluctuations in gold supply were dictated

\footnotetext{
${ }^{33}$ Triffin thought that this situation would lead to the collapse of Bretton Woods and to a deflation. The first of these two implications turned out to be correct. According to Eichengreen (1992), Feliks Mlynarski made a parallel observation in 1929 arguing that once outstanding liabilities to the rest of the world would exceed the US monetary gold stock there would be a run on the dollar, a tightening of monetary policy and depression (see Mlynarski (1929)).
} 
by the vagaries of discoveries in South Africa or the destabilizing schemes of Soviet Russia, but in any case unable to grow with world demand for liquidity, the demand for the dollar was bound to eventually exceed the gold reserves of the Federal Reserve. This left the door open for a run on the dollar. Interestingly, the current situation can be seen in a similar light: in a world where the US can supply the international currency at will, and invests it in illiquid assets, it still faces a confidence risk. There could be a run on the dollar not because investors would fear an abandonment of the gold parity, as in the seventies, but because they would fear a plunge in the dollar exchange rate. In other words, Triffin's analysis does not have to rely on the gold-dollar parity to be relevant."

Hence, Gourinchas \& Rey (2007b) argue that even under our post-1973 flexible exchange rate regime, the international monetary and financial system faces a "New Triffin dilemma". This point is also emphasized by Farhi, Gourinchas \& Rey (2011), Obstfeld (2011), and Farhi \& Maggiori (2018).

The ability of the United States to be a global insurer and act as a global liquidity provider hinges on the capacity of the country to credibly issue safe assets, chiefly government bonds, private sector safe assets having shown their non-robustness during the 2008 crisis $^{34}$. During times of global crisis, US government bonds are at present the only assets able to provide insurance on a large scale (see Gourinchas, Rey \& Govillot (2017)). Those are backed by the fiscal capacity of the US government. Although the gold value of the dollar is no longer fixed like in the Bretton Woods system, there is a growing asymmetry between the fiscal capacity of the United States (the "backing" of US Treasury bills and bonds) and the stock of liquid dollar debt held abroad (for further discussions on the fiscal side of the Triffin dilemma see Obstfeld (2013)). In other words, the sheer size of the gross liquid external debt of the U.S. may be threatening at some point the ability of the U.S. to act as a world banker or insurer. In Gourinchas, Rey \& Govillot (2017), an increase in the demand of safe assets by the rest of the world relative to the decreasing size of the US economy translates into a decrease in the real rate of interest. One can think of many crisis models where fundamentals in extreme regions support only one equilibrium (crisis with probability one, when fundamentals are bad, or no crisis with probability one at the other extreme), while when fundamentals are in an intermediate region self-fulfilling crises are possible. In our specific case, the decline in the relative size of the U.S. over time (or destabilizing US macroeconomic policies) may shift the economy from the no crisis zone to the self-fulfilling crisis zone. Farhi \& Maggiori (2018) share some of these features. They model the hegemon as a "world banker" issuing safe assets with limited commitment and a propensity to inflate in crisis times. The preference of the rest of the world for US safe assets is exogenous so that the role of the dollar in international payments is left unmodeled. They emphasize that banking is a fragile activity that is subject to self-fulfilling runs in an intermediate region of the parameters. Runs in their model are all the more likely that there is no Lender of Last Resort with a sufficient fiscal capacity to back the hegemon.

\footnotetext{
${ }^{34}$ For an analysis of governments as liquidity provider, see the seminal work of Holmström \& Tirole (1998). Gorton (2017) provides an excellent account of the history and economics of safe assets both public and private.
} 
To sum up, there is a "New Triffin dilemma". Just like the Bretton Woods system collapsed with a run on the dollar, the international monetary and financial system could witness a loss of confidence in the value of US debt. As the demand for dollar liquidity keeps growing but the relative size of the US shrinks in the world economy, a new run on the dollar into one or several alternative reserve currencies could be possible. On the one hand, large stocks of dollar liquidity held abroad relative to the size of the U.S. may lead to a loss of confidence in the dollar; on the other hand, too little international dollar liquidity would fail to lubricate the functioning of international financial markets. "Gold or not, the specter of the Triffin dilemma may still be haunting us!" 35

\section{Conclusions}

There are multiple complementarities in the functions of the currency of the hegemon in the international monetary system, from private sector use (invoicing, banking, vehicle currency, bond issuance) to official sector use (peg, reserves, intervention), and vice versa. An essential role of the hegemon is to provide liquidity to lubricate the wheels of international transactions in good and asset markets. Another related key role is to provide insurance in crisis times to the world economy. The hegemon issues large amount of nominally safe securities denominated in its currency in order to perform these two vital tasks. Those liabilities are happily absorbed by the rest of the world most of the time. This implies that the external constraint of the hegemon is relaxed and that its process of external adjustment is greatly facilitated by this large demand for its external liabilities. This is the essence of the exorbitant privilege. A close look at the current hegemon, the United States, in the context of the Bretton Woods system and the post-Bretton Woods system of flexible exchange rates shows that its external balance sheet reflects its role as a world banker or insurer. It benefits from an important valuation channel of adjustment to ensure external solvency, a channel which has increased in power in the last decade. Interestingly, because of the key role the dollar exchange rate plays in the valuation and trade channels of adjustment, it is possible to use measures of external imbalances of the United States to predict future returns on the net foreign asset positions, future export growth and importantly future exchange rate changes at horizons ranging from a quarter to several years for the post Bretton Woods sample.

A growing literature has provided different interpretations and measures of the exorbitant privilege in the context of the United States, from sizable excess returns on the net foreign positions, to deviations from interest rate parity, to liquidity premium and convenience yields or ease of access to capital markets. A number of recent papers highlight that US monetary policy is an important factor driving international trade and the Global Financial Cycle, i.e. comovements in credit creation, capital flows and risky asset prices around the globe. These monetary policy spillovers matter for the conduct of domestic monetary and macroprudential policies. But, as dollar liquidity is omnipresent in international markets, it becomes increasingly obvious, with the decline of the relative size of the US in the world economy, that a "New Triffin dilemma" may emerge. One solution, proposed by several authors, such as e.g. Farhi, Gourinchas \& Rey (2011) and Eichengreen (2011), is the emergence of a more multi-polar international monetary and financial system where multiple governments would issue reserve currencies. While this system would help in overcoming the "New Triffin

\footnotetext{
${ }^{35}$ Gourinchas \& Rey (2007b).
} 
Dilemma", its stability properties are hard to assess ex-ante. As pointed out in Farhi, Gourinchas \& Rey (2011), increased substitutability across key currencies may stabilize relative prices, but it may also lead to massive portfolio shifts whenever confidence in one of the key currency is eroded. This aspect was also pointed out earlier on in Nurkse (1944), who underlines the instability of the international monetary system when two countries (in that case the United States and the United Kingdom) were in competition for the top spot in the inter-war period (see also He, Krishnamurthy \& Milbradt (2019) and Farhi \& Maggiori (2018)). More research on these issues - and the many others raised in this articlewould be desirable. ${ }^{36}$ The reader will have noticed the many interfaces between the subject of this article and some of the most intriguing and important themes in macroeconomic research: external imbalances, macroeconomic adjustment via fiscal and monetary policy, exchange rate dynamics, currency use, capital flows, international spillovers, financial crises and safe assets, are just a few examples. The beauty of studying the international monetary and financial systems lies also in realizing their all encompassing relevance for our economic lives.

\footnotetext{
${ }^{36}$ Insights from the political science, legal and the international relation literatures are crucial to understand more fully the geopolitical implications and power associated with the issuance of a hegemonic currency. We unfortunately could not cover those in this article.
} 


\section{A Appendix}
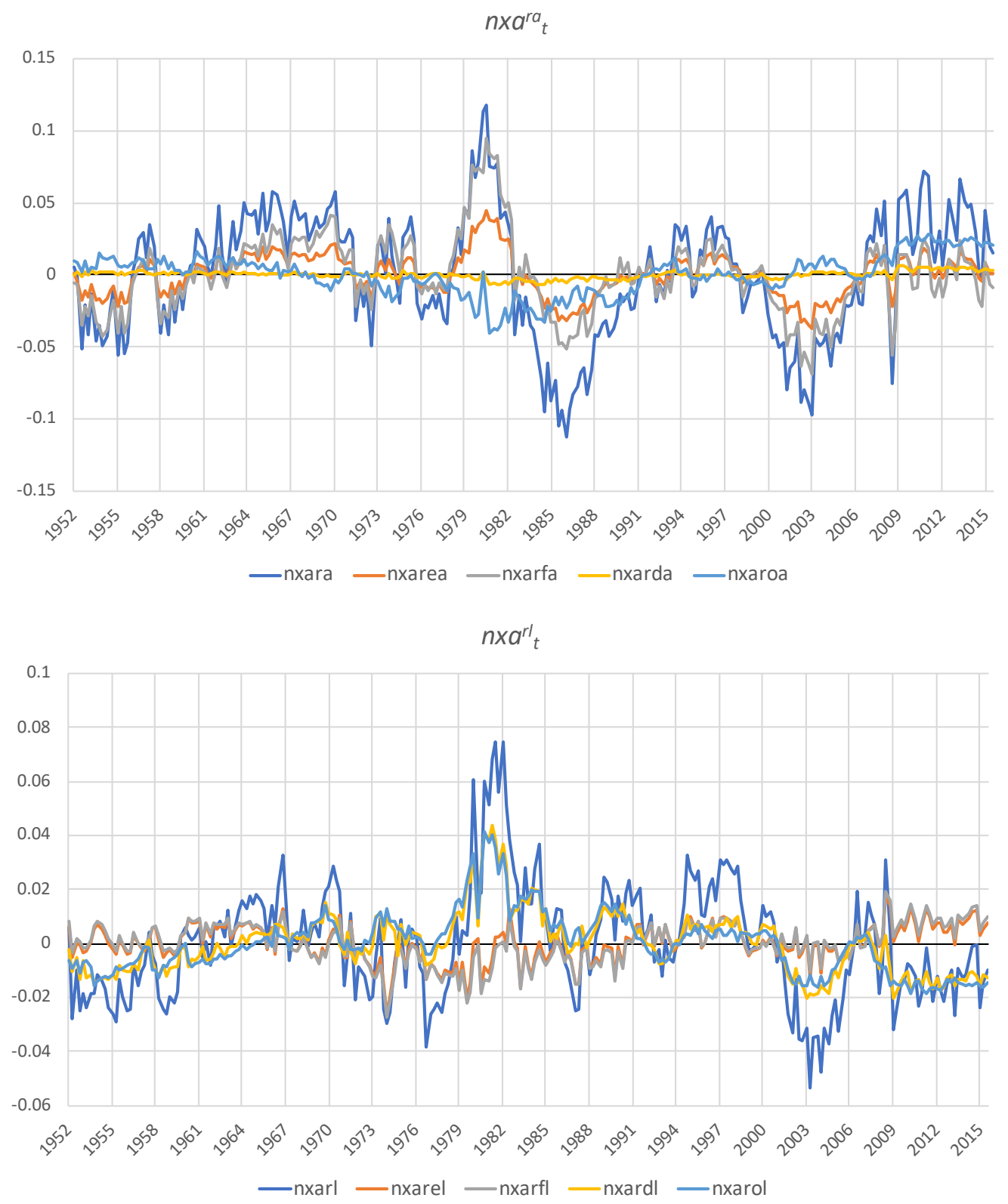

Figure A1: Decomposition of the return on asset component $n x a(r a)$ and the return on liability component $n x a(r l)$ into their subcomponents. 
Table A1: Predictability at several horizons with nxa $\mathbf{a}_{\mathbf{t}}$ and basis measures of Jiang, Krishnamurthy \& Lustig (2018b) - Jiang, Krishnamurthy \& Lustig (2018b) data

\begin{tabular}{|c|c|c|c|c|c|c|c|c|c|}
\hline & \multicolumn{8}{|c|}{ Forecast Horizon (quarters) } \\
\hline & & 1 & 2 & 3 & 4 & 8 & 12 & 16 & 24 \\
\hline \multicolumn{10}{|c|}{ Panel A: Univariate regressions } \\
\hline \multirow[t]{3}{*}{$n x a_{t}$} & coef. & -2.99 & -4.05 & -5.17 & -5.44 & -6.05 & -4.84 & -4.51 & -3.44 \\
\hline & p-value & $(0.40)$ & $(0.19)$ & $(0.06)$ & $(0.03)$ & $(0.00)$ & $(0.00)$ & $(0.00)$ & $(0.00)$ \\
\hline & $\operatorname{adj} .-R^{2}$ & {$[0.00]$} & {$[0.01]$} & {$[0.05]$} & {$[0.08]$} & {$[0.26]$} & {$[0.29]$} & {$[0.39]$} & {$[0.30]$} \\
\hline \multirow[t]{3}{*}{$x_{t}^{\text {Treas }}$} & coef. & 3.44 & 0.06 & -3.90 & -5.00 & -2.96 & -3.49 & -2.24 & -1.96 \\
\hline & p-value & $(0.57)$ & $(0.99)$ & $(0.31)$ & $(0.20)$ & $(0.21)$ & $(0.02)$ & $(0.12)$ & $(0.08)$ \\
\hline & $\operatorname{adj} .-R^{2}$ & {$[0.04]$} & {$[0.01]$} & {$[0.04]$} & {$[0.04]$} & {$[0.00]$} & {$[0.04]$} & {$[0.02]$} & {$[0.02]$} \\
\hline \multirow[t]{3}{*}{$\Delta x_{t}^{\text {Treas }}$} & coef. & 2.26 & 2.84 & 6.79 & 7.14 & 3.64 & 3.69 & 2.37 & 2.22 \\
\hline & p-value & $(0.76)$ & $(0.63)$ & $(0.13)$ & $(0.09)$ & $(0.10)$ & $(0.01)$ & $(0.10)$ & $(0.06)$ \\
\hline & $\operatorname{adj} .-R^{2}$ & {$[0.04]$} & {$[0.01]$} & {$[0.04]$} & {$[0.04]$} & {$[0.00]$} & {$[0.04]$} & {$[0.02]$} & {$[0.02]$} \\
\hline \multirow[t]{3}{*}{$\Delta x_{t-1}^{\text {Treas }}$} & coef. & -1.72 & 1.44 & 2.93 & 2.59 & 1.23 & 1.24 & 0.79 & 0.89 \\
\hline & p-value & $(0.64)$ & $(0.58)$ & $(0.20)$ & $(0.21)$ & $(0.24)$ & $(0.07)$ & $(0.19)$ & $(0.08)$ \\
\hline & $\operatorname{adj} .-R^{2}$ & {$[0.04]$} & {$[0.01]$} & {$[0.04]$} & {$[0.04]$} & {$[0.00]$} & {$[0.04]$} & {$[0.02]$} & {$[0.02]$} \\
\hline \multirow{3}{*}{$x_{t}^{L I B O R}$} & coef. & 0.42 & 0.12 & 1.28 & 1.63 & 0.84 & 0.87 & 0.49 & 2.47 \\
\hline & p-value & $(0.94)$ & $(0.98)$ & $(0.79)$ & $(0.70)$ & $(0.76)$ & $(0.62)$ & $(0.73)$ & $(0.01)$ \\
\hline & $\operatorname{adj} .-R^{2}$ & {$[0.11]$} & {$[0.06]$} & {$[0.02]$} & {$[-0.01]$} & {$[-0.02]$} & {$[-0.02]$} & {$[-0.01]$} & {$[0.06]$} \\
\hline \multirow[t]{3}{*}{$\Delta x_{t}^{L I B O R}$} & coef. & 10.82 & 6.66 & 2.55 & 0.35 & -0.19 & -0.25 & 0.26 & -2.30 \\
\hline & p-value & $(0.04)$ & $(0.17)$ & $(0.55)$ & $(0.93)$ & $(0.95)$ & $(0.90)$ & $(0.86)$ & $(0.04)$ \\
\hline & $\operatorname{adj} .-R^{2}$ & {$[0.11]$} & {$[0.06]$} & {$[0.02]$} & {$[-0.01]$} & {$[-0.02]$} & {$[-0.02]$} & {$[-0.01]$} & {$[0.06]$} \\
\hline \multirow{3}{*}{$\Delta x_{t-1}^{L I B O R}$} & coef. & 2.29 & 0.26 & -1.50 & -1.33 & -0.95 & -0.49 & -0.26 & -1.39 \\
\hline & p-value & $(0.40)$ & $(0.90)$ & $(0.47)$ & $(0.50)$ & $(0.53)$ & $(0.62)$ & $(0.73)$ & $(0.03)$ \\
\hline & $\operatorname{adj} .-R^{2}$ & {$[0.11]$} & {$[0.06]$} & {$[0.02]$} & {$[-0.01]$} & {$[-0.02]$} & {$[-0.02]$} & {$[-0.01]$} & {$[0.06]$} \\
\hline \multicolumn{10}{|c|}{ Panel B: Multivariate regressions } \\
\hline \multirow[t]{2}{*}{$n x a_{t}$} & coef. & -4.24 & -5.10 & -6.57 & -7.01 & -6.93 & -5.39 & -4.81 & -3.94 \\
\hline & p-value & $(0.17)$ & $(0.06)$ & $(0.01)$ & $(0.00)$ & $(0.00)$ & $(0.00)$ & $(0.00)$ & $(0.00)$ \\
\hline \multirow[t]{2}{*}{$x_{t}^{\text {Treas }}$} & coef. & 11.25 & 2.39 & -3.77 & -3.75 & -1.79 & -4.68 & -2.93 & -1.32 \\
\hline & p-value & $(0.16)$ & $(0.61)$ & $(0.35)$ & $(0.35)$ & $(0.47)$ & $(0.01)$ & $(0.06)$ & $(0.26)$ \\
\hline \multirow{2}{*}{$x_{t}^{L I B O R}$} & coef. & -11.63 & -5.49 & -3.37 & -6.28 & -6.99 & -0.54 & -0.96 & 0.58 \\
\hline & p-value & $(0.31)$ & $(0.53)$ & $(0.65)$ & $(0.36)$ & $(0.05)$ & $(0.85)$ & $(0.69)$ & $(0.70)$ \\
\hline \multirow[t]{2}{*}{$\Delta x_{t}^{\text {Treas }}$} & coef. & -9.58 & -2.29 & 6.01 & 6.34 & 3.06 & 4.91 & 2.87 & 1.58 \\
\hline & p-value & $(0.27)$ & $(0.65)$ & $(0.16)$ & $(0.13)$ & $(0.22)$ & $(0.01)$ & $(0.06)$ & $(0.20)$ \\
\hline \multirow[t]{2}{*}{$\Delta x_{t}^{L I B O R}$} & coef. & 20.33 & 11.93 & 5.13 & 5.52 & 5.74 & 0.36 & 1.20 & -1.01 \\
\hline & p-value & $(0.10)$ & $(0.22)$ & $(0.47)$ & $(0.40)$ & $(0.10)$ & $(0.90)$ & $(0.60)$ & $(0.47)$ \\
\hline \multirow[t]{2}{*}{$\Delta x_{t-1}^{\text {Treas }}$} & coef. & -6.34 & 1.94 & 5.07 & 3.36 & 1.62 & 2.21 & 1.40 & 0.93 \\
\hline & p-value & $(0.18)$ & $(0.46)$ & $(0.05)$ & $(0.12)$ & $(0.20)$ & $(0.03)$ & $(0.07)$ & $(0.18)$ \\
\hline \multirow[t]{3}{*}{$\Delta x_{t-1}^{L I B O R}$} & coef. & 8.37 & -0.14 & -2.83 & 0.08 & 1.03 & -0.66 & -0.22 & -1.17 \\
\hline & p-value & $(0.20)$ & $(0.97)$ & $(0.38)$ & $(0.98)$ & $(0.56)$ & $(0.56)$ & $(0.84)$ & $(0.15)$ \\
\hline & $\operatorname{adj} .-R^{2}$ & {$[0.11]$} & {$[0.08]$} & {$[0.13]$} & {$[0.17]$} & {$[0.34]$} & {$[0.37]$} & {$[0.43]$} & {$[0.45]$} \\
\hline
\end{tabular}

Notes: Cf. below. 
Notes for Table A1: The dependent variable is the depreciation rate (minus appreciation rate), $\Delta e_{t, k}=e_{t+k}-e_{t}$. $d i_{t}$ from Jiang, Krishnamurthy \& Lustig (2018b). Sample: 1988Q1-2015Q4. $n x a_{t}$ weights are computed on the full sample (1952Q1-2015Q4). Panel A presents the results for univariate regressions of the form $\Delta e_{t, k}=\alpha+\beta v+\epsilon_{t}$ with $v \in\left\{n x a_{t}, x_{t}^{\text {Treas }}, x_{t}^{L I B O R}, d i_{t}\right\}$. For Panel A regressions on each $x_{t}$, the corresponding $\Delta x_{t}$ and $\Delta x_{t-1}$ are also included as controls. Panel $\mathrm{B}$ presents the results for multivariate regressions of $\Delta e_{t, k}$ on all variables together, also controlling for interest rate differential. Standard-errors are computed using Newey-West with Bartlett windows of $k-1$ quarters, and p-values reported in parentheses. Boldface entries are significant at the 5 percent level. All coefficients are multiplied by 100, and basis measures are expressed in percentage points to make the magnitude of the coefficients broadly comparable (in terms of the effect of a 1-standard deviation change). 


\section{References}

Alogoskoufis, George and Richard Portes (1991). International costs and benefits from EMU. European Economy, Special Edition No. 1, Pt. 5, pp. 231-245.

Avdjiev S, McCauley RN, Shin HS. (2015). Breaking free of the triple coincidence in international finance. Work. Pap. 524, Bank Int. Settl., Basel, Switz.

Avdjiev S, Du W, Koch C, Shin HS. (2016). Exchange rates, currency hedging and the cross-currency basis. Work. Pap. 592, Bank Int. Settl., Basel, Switz.

Bahaj, Saleem, and Ricardo Reis (2018). Central Bank Swap Lines. Discussion Papers 1816, Centre for Macroeconomics (CFM).

Baskaya, Yusuf Soner, Julian di Giovanni, Sebnem Kalemli Ozcan, and Mehmet Fatih Ulu (2017) International spillovers and local credit cycle, NBER Working Papers 23149, National Bureau of Economic Research, Inc.

Bernanke, Ben S. (2017). Federal Reserve Policy in an International Context. IMF Economic Review, Vol. 65, No. 1, pp. 5-36, April.

Betts, Caroline. and Devereux, Michael. (2000). Exchange rate dynamics in a model of pricing-to- market. Journal of International Economics, 50(1):215-44.

Bank for International Settlements. (2016). Downsized FX markets: causes and implications. BIS Quarterly Review, Dec:35-51.

Bordo, Michael D., and Robert N. McCauley (2018). Triffin: dilemma or myth?. NBER Working Papers 24195, National Bureau of Economic Research, Inc.

Borio, Claudio and Zhu H (2008). Capital regulation, risk-taking and monetary policy: a missing link in the transmission mechanism? Work. Pap. 268, Bank Int. Settl., Basel, Switz.

Bruno, Valentina and Shin, Hyun Song (2015). Capital flows and the risk-taking channel of monetary policy. Journal of Monetary Economics, 71, issue C, p. 119-132.

Bruno, Valentina, Se-Jik Kim, and Hyun Shin (2018). Exchange Rates and the Working Capital Channel of Trade Fluctuations. AEA Papers and Proceedings, 108 : 531-36.

Caballero, Ricardo J., Emmanuel Farhi, and Pierre-Olivier Gourinchas (2008). An Equilibrium Model of "Global Imbalances" and Low Interest Rates. American Economic Review, American Economic Association, vol. 98(1), pages 358-393, March.

Caballero, Ricardo J., Emmanuel Farhi, and Pierre-Olivier Gourinchas (2016). Safe Asset Scarcity and Aggregate Demand. American Economic Review, American Economic Association, vol. 106(5), pages 513-518, May.

Caballero, Ricardo J., Emmanuel Farhi, and Pierre-Olivier Gourinchas (2017). The Safe Assets Shortage Conundrum. Journal of Economic Perspectives, American Economic Association, vol. 31(3), pages 29-46, Summer. 
Calvo, Guillermo A. (1988). Servicing the public debt: The role of expectations. The American Economic Review, 647-661.

Calvo, Guillermo A., Leonardo Leiderman, and Carmen M. Reinhart (1996). Inflows of Capital to Developing Countries in the 1990s, Journal of Economic Perspectives, vol. 10, No. 2, pp. 123-139.

Camanho, Nelson, and Harald Hau, and Hélène Rey, 2018. Global Portfolio Rebalancing and Exchange Rates. NBER Working Papers 24320, National Bureau of Economic Research, Inc.

Campbell, John Y., and Robert Shiller (1988). The Dividend-Price Ratio and Expectations of Future Dividends and Discount Factors. Review of Financial Studies, 1 (Fall): 195-228.

Cetorelli, N., and Goldberg, L. S. (2012). Banking Globalization and Monetary Transmission. The Journal of Finance, 67: 1811-1843.

Cecchetti, Stephen, Tommaso Mancini Griffoli and Machiko Narita (2017). Does Prolonged Monetary Policy Easing Increase Financial Vulnerability? IMF Working Paper No. 17/65.

Charhour, Ryan and Rosen Valchev (2018). International Medium of Exchange: Privilege and Duty.Manuscript Boston College.

Chinn Menzie and Jeffrey A. Frankel (2007). Will the Euro Eventually Surpass the Dollar as Leading International Reserve Currency? Gry current account imbalances: sustainability and adjustment, University of Chicago Press.

Cochrane, John H. (1992). Explaining the Variance of Price-Dividend Ratios. Review of Financial Studies, 5 (2): 243-80.

Cohen, B. J. (1971). The future of sterling as an international currency. Macmillan, London.

Cohen, Benjamin H., Dietrich Domanski, Ingo Fender, and Hyun Song Shin (2017). Global liquidity: A selective review. Annual Review of Economics, 9: 587-612.

Corsetti, G., Dedola, L., and Leduc, S. (2010). Chapter 16 - optimal monetary policy in open economies? volume 3 of Handbook of Monetary Economics, pages 861-933. Elsevier.

Curcuru, S.E., Dvorak, T., Warnock, F.E. (2008). Cross-border returns differentials. Quarterly Journal of Economics 123 (4), 1495-1530.

Despres, E., C.P. Kindleberger, and W.S. Salant (1966). The Dollar and World Liquidity: A Minority View. Brookings Institution, Reprint, Brookings Institution.

European Central Bank (2018). The international role of the euro. Interim report, June 2018, Frankfurt am Main.

Eichengreen, Barry (1992). Golden fetters: the gold standard and the Great Depression, 1919-1939. Oxford: Oxford University Press.

Eichengreen, Barry (2011). Exorbitant Privilege: The Rise and Fall of the Dollar and the Future of the International Monetary System. Oxford University Press, January 2011. 
Eichengreen Barry, Arnaud Mehl, and Livia Chitu (2017). How Global Currencies Work: Past, Present, and Future. Princeton University Press, November 2017.

Engel Charles and Steve Pak Yeung Wu (2019). Liquidity and Exchange Rates: An Empirical Investigation. mimeo University of Wisconsin, January 2019.

Farhi, Emmanuel, Pierre-Olivier Gourinchas, and Hélène Rey (2011). Reforming the International Monetary System. Centre for Economic Policy Research, 76.

Farhi, Emmanuel, and Matteo Maggiori. A Model of the International Monetary System. Quarterly Journal of Economics, 133, no. 1 (2018): 295-355.

Froot, Kenneth A., and Rogoff, Kenneth (1995). Perspectives on PPP and long-run real exchange rates. In: G. M. Grossman \& K. Rogoff (ed.), Handbook of International Economics, edition 1, volume 3, chapter 32, pages 1647-1688, Elsevier.

Gerko, Elena and Hélène Rey (2017). Monetary policy in the capitals of capital. Journal of the European Economic Association, Volume 15, Issue 4, 1, August, Pages 721-745.

Gertler, M., S. Gilchrist, and F. Natalucci (2007): "External Constraints on Monetary Policy and the Financial Accelerator," Journal of Money, Credit and Banking, 39, 295-330.

Goldberg, Linda, and Cédric Tille (2009). Macroeconomic interdependence and the international role of the dollar. Journal of Monetary Economics, Volume 56, Issue 7, Pages 990-1003, ISSN 0304-3932.

Gopinath, Gita (2016). The International Price System. Jackson Hole Symposium Proceedings.

Gopinath, Gita, Emine Boz, Camila Casas, Federico Diez, Pierre-Olivier Gourinchas and Mikkel Plagborg-Møller (2018). Dominant Currency Paradigm. NBER Working Paper No. 22943 Issued in December 2016, Revised in December 2018.

Gopinath, Gita, and Jeremy C. Stein (2018). Banking, Trade, and the Making of a Dominant Currency. NBER Working Paper, No. w24485. April 2018.

Gopinath, Gita, and Jeremy C. Stein (2018). Trade Invoicing, Bank Funding, and Central Bank Reserve Holdings. AEA Papers and Proceedings, 108 : 542-46.

Gorton, Gary (2017). The History and Economics of Safe Assets. Annual Review of Economics, vol 9(1), pages 547-586.

Gourinchas, Pierre-Olivier (2012). Global Imbalances and Global Liquidity. in Asia's Role in the Post-Crisis Global Economy, Asian Economic Policy Conference, R. Glick and M. Spiegel eds., pages 305-340, San Francisco Federal Reserve.

Gourinchas, Pierre-Olivier (2018). Monetary Policy Transmission in Emerging Markets: An Application to Chile, in: E. Mendoza, E. Pastén \& D. Saravia (ed.), Monetary Policy and Global Spillovers: Mechanisms, Effects and Policy Measures, edition 1, volume 25, chapter 8, pages 279-324 Central Bank of Chile. 
Gourinchas, Pierre-Olivier, and Hélène Rey (2007a). International Financial Adjustment. Journal of Political Economy, University of Chicago Press, vol. 115(4), pages 665-703, August.

Gourinchas, Pierre-Olivier, and Hélène Rey (2007b). From world banker to world venture capitalist: US external adjustment and the exorbitant privilege. Gry current account imbalances: sustainability and adjustment, University of Chicago Press, pages 11-66.

Gourinchas, Pierre-Olivier, Hélène Rey, and Kai Truempler (2012). The financial crisis and the geography of wealth transfers. Journal of International Economics, Elsevier, vol. 88(2), pages 266-283.

Gourinchas, Pierre-Olivier, and Hélène Rey (2014). External Adjustment, Global Imbalances, Valuation Effects. Handbook of International Economics, Elsevier.

Gourinchas, Pierre-Olivier, Hélène Rey, and Nicolas Govillot (2017). Exorbitant Privilege and Exorbitant Duty. Working paper, 2017.

Hartmann, P. (1998). Currency Competition and Foreign Exchange Markets: The Dollar, the Yen and the Euro. Cambridge University Press.

Hassan, T. A. (2013). Country Size, Currency Unions, and International Asset Returns. The Journal of Finance, 68: 2269-2308.

Hau, Harald, and Hélène Rey (2004). Can Portfolio Rebalancing Explain the Dynamics of Equity Returns, Equity Flows, and Exchange Rates? American Economic Review, 94 (2): $126-133$.

Hau, Harald, and Hélène Rey (2006). Exchange Rates, Equity Prices, and Capital Flows. The Review of Financial Studies, Volume 19, Issue 1, 1 March 2006, pages 273-317.

He, Zhiguo, Arvind Krishnamurthy, and Konstantin Milbradt (2019). A Model of Safe Asset Determination. American Economic Review, 109 (4): 1230-62.

Holmström B, and Tirole J. (1998). Private and public supply of liquidity. Journal of Political Economy, 106:1-40.

Ilzetzki, Ethan, Reinhart, Carmen and Rogoff, Kenneth (2017). Exchange Arrangements Entering the 21st Century: Which Anchor Will Hold?. NBER Working Papers, No 23134, National Bureau of Economic Research, Inc,

Jevons, W.S. (1875). Money and the Mechanism of Exchange, Chapter 1, paragraphs 5-6. London: Macmillan.

Jiang, Zhengyang, Arvind Krishnamurthy, and Hanno Lustig (2018a). Foreign Safe Asset Demand for US Treasuries and the Dollar. AEA Papers and Proceedings, 108 : 537-41.

Jiang, Zhengyang, Arvind Krishnamurthy, and Hanno Lustig (2018b). Foreign Safe Asset Demand and the Dollar Exchange Rate. NBER Working Papers 24439, National Bureau of Economic Research, Inc. 
Jorda, Òscar and Schularick, Moritz and Taylor, Alan M and Ward, Felix (2018). Global Financial Cycles and Risk Premiums. NBER Working Papers 24677, National Bureau of Economic Research, Inc.

Kenen, Peter B. (1960). International liquidity and the balance of payments of a reservecurrency country. The Quarterly Journal of Economics, 572-586.

Kenen, Peter B. (1983) The Role of the Dollar as an International Currency. Occasional Paper 13, Group of Thirty, New York.

Kenen, Peter B. (2003). The euro and the dollar: Competitors or complements? In: Dumoulin, M., Duchenne, G. (Eds.), The European Union and the United States. International Monetary Fund, pp. 251-274.

Kindleberger, Charles P. (1976). Systems of International Economic Organization. In: David P. Calleo (ed.), Money and the Coming World Order. New York: New York University Press, 15-39.

Kindleberger, Charles P. (1981). International money. London: George Allen \& Unwin.

Kiyotaki, Nobuhiro, and Randall Wright (1989). On money as a medium of exchange. Journal of Political Economy, 97, pp. 927-54.

Krishnamurthy, Arvind, and Annette Vissing-Jorgensen (2011). The Effects of Quantitative Easing on Interest Rates: Channels and Implications for Policy. Brookings Papers on Economic Activity, 2011, 43 (2 (Fall)), 215-287.

Krishnamurthy, Arvind, and Annette Vissing-Jorgensen (2012). The Aggregate Demand for Treasury Debt. Journal of Political Economy, 120 (2): 233-67.

Krugman, Paul R. (1980). Vehicle currencies and the structure of international exchange. Journal of Money, Credit, and Banking, 125, 13-26.

Krugman, Paul R. (1984). The International Role of the Dollar: Theory and Prospect. NBER Chapters, in: Exchange Rate Theory and Practice, John F. O. Bilson and Richard C. Marston, eds., pages 261-278, National Bureau of Economic Research, Inc.

Lagos, R., and Wright, R. (2005). A Unified Framework for Monetary Theory and Policy Analysis. Journal of Political Economy, 113(3), 463-484. doi:10.1086/429804.

Lane, Philip R., and Gian Maria Milesi-Ferretti (2001).The external wealth of nations:measures of foreign assets and liabilities for industrial and developing countries. Journal of International Economics 55, 263-294.

Lane, Philip R., and Gian Maria Milesi-Ferretti (2007). The external wealth of nations mark II: revised and extended estimates of foreign assets and liabilities,1970-2004. Journal of International Economics 73 (2),223-250.

Lane, P. R. and Milesi-Ferretti, G. M. (2009). Where did all the borrowing go? a forensic analysis of the u.s. external position. Journal of the Japanese and International Economies, 23(2):177-199. 
Lane, Philip R., and Gian Maria Milesi-Ferretti (2018). The External Wealth of Nations Revisited: International Financial Integration in the Aftermath of the Global Financial Crisis. IMF Economic Review, Palgrave Macmillan; International Monetary Fund, vol. 66(1), pages 189-222, March.

Maggiori, Matteo (2017). Financial Intermediation, International Risk Sharing, and Reserve Currencies. American Economic Review, American Economic Association, vol. 107(10), pages 3038-3071, October.

Maggiori, Matteo, Brent Neiman, and Jesse Schreger (2018). International Currencies and Capital Allocation. Working Paper.

Matsuyama, K., Kiyotaki, N., and Matsui, A. (1993). Toward a Theory of International Currency. The Review of Economic Studies, 60(2), 283-307.

McKinnon, R. (1979). Money in international exchange. Oxford University Press, New York.

Meese, Richard A., and Kenneth Rogoff (1983). Empirical Exchange Rate Models of the Seventies: Do They Fit Out of Sample? Journal of International Economics, 14 (February): $3-24$.

Mendoza, E. G., Quadrini, V., and Ríos-Rull, J.-V. (2009). Financial integration, financial development, and global imbalances. Journal of Political Economy, 117(3):371-416.

Miranda-Agrippino, Silvia, and Hélène Rey (2018). US Monetary Policy and the Global Financial Cycle. NBER Working Paper No. 21722, Issued in November 2015, Revised in February 2018.

Mlynarski, Feliks (1929). Gold and Central Banks. London: Macmillan, 1929.

Morais, Bernardo, Peydró, José-Luis, Roldán-Peña Jessica, and Ruiz, Claudia (forthcoming). The International Bank Lending Channel of Monetary Policy Rates and QE: Credit Supply, Reach-for-Yield, and Real Effects. The Journal of Finance, forthcoming.

Mukhin, Dmitry (2017). An equilibrium model of the International Price System. Manuscript, Princeton University.

Mundell, Robert A. (1968). International Economics. New York: Macmillan.

Nurkse, Ragnar (1944). International currency experience: lessons of the interwar period. League of Nations.

Obstfeld, M. and Rogoff, K. (1995). Exchange rate dynamics redux. Journal of Political Economy, 103:624-60.

Obstfeld, Maurice (2011). International Liquidity: The Fiscal Dimension. NBER Working Papers, 17379, National Bureau of Economic Research, Inc.

Obstfeld, Maurice (2013). The International Monetary System: Living with Asymmetry. NBER Chapters, in: Globalization in an Age of Crisis: Multilateral Economic Cooperation in the Twenty-First Century, pages 301-336 National Bureau of Economic Research, Inc. 
Obstfeld, Maurice, Jay C. Shambaugh and Alan M. Taylor (2010). Financial Stability, the Trilemma, and International Reserves. American Economic Journal: Macroeconomics. vol. 2(2,April), pages 57-94.

Papaioannou, Elias, Portes, Richard, and Siourounis, Gregorios (2006). Optimal currency shares in international reserves: The impact of the euro and the prospects for the dollar. Journal of the Japanese and International Economies, Elsevier, vol. 20(4), pages 508-547, December.

Portes, Richard (2012). A reassessment of the Triffin Dilemma. In J-C Koeune, ed., In search of a new world monetary order: Proceedings of a conference to celebrate the 100th anniversary of Robert Triffin (1911-1993). P.I.E. Peter Lang.

Portes, Richard, and Rey, Hélène (1998). The emergence of the euro as an international currency. Economic Policy 26, 307-343. (April).

Rey, Hélène (2001). International trade and currency exchange. The Review of Economic Studies 68.2 (2001): 443-464.

Rey, Hélène (2013). Dilemma not Trilemma: The Global Financial Cycle and Monetary Policy Independence. Federal Reserve Bank of Kansas City Economic Policy Symposium (2013).

Rey, Hélène (2016). International Channels of Transmission of Monetary Policy and the Mundellian Trilemma. IMF Economic Review, 2016, 64:6.

Rogoff, Kenneth S. (1998). Blessing or Curse? Foreign and Underground Demand for Euro Notes. Economic Policy 13 (26): 263-303.

Rogoff, Kenneth S. (2014). Costs and Benefits to Phasing Out Paper Currency. NBER Working Paper 20126. National Bureau of Economic Research (Cambridge, Mass.).

Rogoff, Kenneth S. (2017). The Curse of Cash: How Large-Denomination Bills Aid Crime and Tax Evasion and Constrain Monetary Policy. Princeton Univeristy Press.

Triffin, Robert (1961). Gold and the Dollar Crisis: The future of convertibility. Yale University Press, New Haven, Connecticut.

Verdelhan, A. (2018). The Share of Systematic Variation in Bilateral Exchange Rates. The Journal of Finance, 73: 375-418.

Zhou, R. (1997). Currency Exchange in a Random Search Model. The Review of Economic Studies, 64(2), 289-310. 